\title{
Spectroscopic Investigation of the Activation of a Chromium- Pyrrolyl Ethene Trimerization Catalyst
}

\author{
Bas Venderbosch, ${ }^{\dagger}$ Jean-Pierre H. Oudsen, ${ }^{\dagger}$ Lukas A. Wolzak, ${ }^{\dagger}$ David J. Martin, ${ }^{\dagger}$ (๑) Ties J. Korstanje, \\ and Moniek Tromp $*, \dagger, \S(0)$
}

${ }^{\dagger}$ Sustainable Materials Characterization, van ’t Hoff Institute for Molecular Sciences (HIMS), University of Amsterdam, Science Park 904, 1098 XH Amsterdam, The Netherlands

Supporting Information

\begin{abstract}
Hexene is an important $\alpha$-olefin for polyethylene production and is produced from ethene. Recent developments in the $\alpha$-olefin industry have led to the successful commercialization of ethene trimerization catalysts. An important industrially applied ethene trimerization system uses a mixture of chromium 2-ethylhexanoate, $\mathrm{AlEt}_{3}, \mathrm{AlEt}_{2} \mathrm{Cl}$, and 2,5-dimethylpyrrole (DMP). Here, we have studied the activation of this system using catalytic and spectroscopic experiments (XAS, EPR, and UV-vis) under conditions employed in industry. First, chromium 2-ethylhexanoate was prepared and characterized to be $\left[\mathrm{Cr}_{3} \mathrm{O}\left(\mathrm{RCO}_{2}\right)_{6}\left(\mathrm{H}_{2} \mathrm{O}\right)_{3}\right] \mathrm{Cl}$. Next, the activation of chromium 2-ethylhexanoate with $\mathrm{AlEt}_{3}, \mathrm{AlEt}_{2} \mathrm{Cl}$, and $\mathrm{DMP}$ was studied,

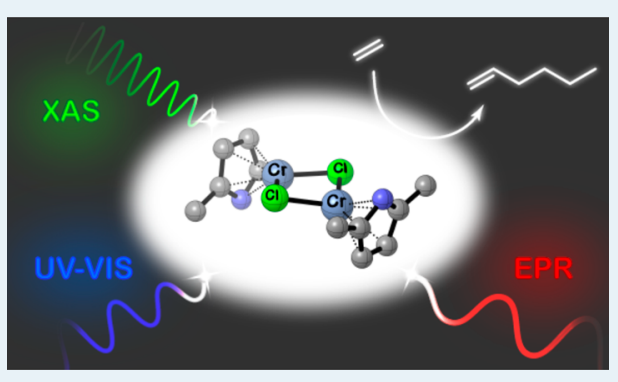
showing immediate reduction $(<5 \mathrm{~ms})$ of the trinuclear $\mathrm{Cr}$ (III) carboxylate and formation of a neutral polynuclear $\mathrm{Cr}$ (II) carboxylate complex. Over time, this $\mathrm{Cr}$ (II) carboxylate complex is partially converted into a chloro-bridged dinuclear Cr(II) pyrrolyl complex. In cyclohexane, small quantities of an unknown $\mathrm{Cr}(\mathrm{I})$ complex $(\sim 1 \%$ after $1 \mathrm{~h})$ are observed, while in toluene, the quantity of $\mathrm{Cr}(\mathrm{I})$ is much higher $(\sim 23 \%$ after $1 \mathrm{~h})$. This is due to the formation of cationic bis(tolyl)Cr(I) complexes, which likely leads to the observed inferior performance using toluene as the reaction solvent. Catalytic studies allow us to exclude some of the observed $\mathrm{Cr}(\mathrm{I})$ and $\mathrm{Cr}$ (II) complexes as the active species in this catalytic system. Using this combination of techniques, we have been able to structurally characterize complexes of this selective $\mathrm{Cr}$-catalyzed trimerization system under conditions which are employed in industry.
\end{abstract}

KEYWORDS: ethene trimerization, chromium, spectroscopy, XAS, EPR, time-resolved

\section{INTRODUCTION}

Linear $\alpha$-olefins (LAOs) enjoy a wide range of applications, for example, in the production of plastics, detergents and surfactants. ${ }^{1}$ Typically, LAOs are produced by catalysts operating via a mechanism which gives rise to a statistical product distribution. ${ }^{2}$ However, the demand for the shorter LAOs (1-butene, 1-hexene, and 1-octene) is rising due to their application in the production of linear low-density polyethylene (LLDPE). ${ }^{3}$ As a result of this changing market demand, companies such as Sasol and Chevron Phillips Chemical have developed catalytic chromium systems, which can selectively trimerize ethene to form 1-hexene. ${ }^{4,5}$ Selective ethene trimerization is believed to proceed via metallacyclic intermediates (see Scheme 1); experimental evidence for this mechanism has been found in deuterium labeling experiments. ${ }^{6}$ The oxidation state of the metal during the catalytic cycle however is subject to debate, and different experiments have suggested either a $\mathrm{Cr}(\mathrm{I}) / \mathrm{Cr}(\mathrm{III})^{7-9}$ or a $\mathrm{Cr}(\mathrm{II}) /$ $\mathrm{Cr}(\mathrm{IV})^{10-12}$ redox couple. Gaining insights into the oxidation states of chromium during the catalytic cycle is complicated by the paramagnetic nature of the various oxidation states of chromium formed in these reactions. ${ }^{13}$ Strategies to probe the oxidation state of chromium involves the application of spectroscopic techniques such as electron paramagnetic
Scheme 1. Proposed Mechanism for the Selective Formation of 1-Hexene via Metallacyclic Intermediates

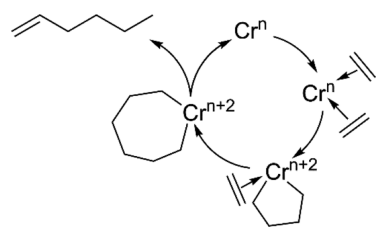

resonance (EPR) and X-ray absorption spectroscopy $(\mathrm{XAS})^{10,14,15}$ and crystallization of self-activating catalysts. ${ }^{7,8,16}$

The first ethene trimerization system was successfully commercialized by Chevron Phillips Chemical in Qatar (2003); annually $47000 \mathrm{t}$ of 1 -hexene is produced in this plant. The system consists of chromium 2-ethylhexanoate, 2,5dimethylpyrrole (DMP), $\mathrm{AlEt}_{3}$, and $\mathrm{AlEt}_{2} \mathrm{Cl}$ mixed in a molar ratio of 1:3:11:8, respectively (see Scheme 2). ${ }^{17}$ Despite successful commercialization, limited mechanistic studies have been reported in open academic literature. Duchateau and

Received: August 25, 2018

Revised: December 17, 2018

Published: December 20, 2018 
Scheme 2. Preparation of the Chevron Phillips Chemical Trimerization System via Mixing of $\mathrm{Cr}(2-\mathrm{EH})_{3}$ and $\mathrm{DMP}, \mathrm{AlEt}_{3}$, and $\mathrm{AlEt}_{2} \mathrm{Cl}$ in a Molar Ratio of 1:3:11:8, Respectively

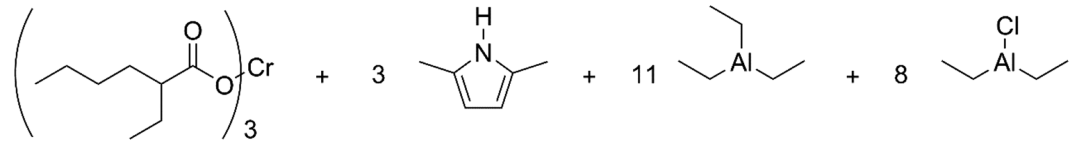

Korobkov and co-workers have successfully isolated $\mathrm{Cr}(\mathrm{I})$, $\mathrm{Cr}(\mathrm{II})$ and $\mathrm{Cr}(\mathrm{III})$ pyrrolyl complexes; some of these complexes were found to be self-activating ethene trimerization catalysts (see Scheme 3 for an overview). On the basis of the

Scheme 3. Overview of Self-Activation Chromium-Pyrrolyl Ethene Trimerization Catalysts in the (a) $\mathrm{Cr}(\mathrm{I})$, (b) $\mathrm{Cr}$ (II), and (c) $\mathrm{Cr}$ (III) Oxidation State $\mathrm{e}^{7,8,18}$ a

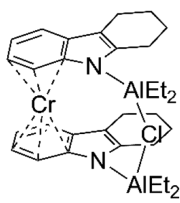

b

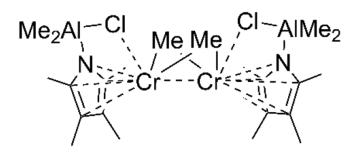

C

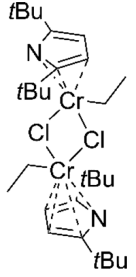

observed catalytic performance of these complexes, the authors propose a $\mathrm{Cr}(\mathrm{I}) / \mathrm{Cr}(\mathrm{III})$ redox couple to be responsible for catalysis. ${ }^{7,8,18}$ None of the complexes was however isolated under the exact conditions employed in industry, and different sources of chromium, aluminum alkyl reagents and ligands have been used. In another study by Skobelev et al., performed in the presence of ethene, a correlation between $\mathrm{Cr}(\mathrm{I})$ concentration and catalytic activity was found using EPR spectroscopy, again in favor of a $\mathrm{Cr}(\mathrm{I}) / \mathrm{Cr}$ (III) redox couple. ${ }^{9}$ The performed EPR experiments however did not provide insights in the structure of the formed $\mathrm{Cr}(\mathrm{I})$ complexes nor in the structure of the large quantity of EPR-silent complexes formed.

XAS has been shown to be a useful spectroscopic technique which allows for the determination of both oxidation state and structure of homogeneous catalysts. ${ }^{19}$ A combination of XAS and EPR was successfully applied by Brückner and co-workers to study a $\mathrm{Cr}-\{\mathrm{PNP}\}$ tetramerization system. In the performed study, they propose the active species to be a (PNP) $\mathrm{Cr}(\mathrm{II})\left(\mathrm{CH}_{3}\right)_{2}$ complex; deactivation of the catalyst can occur via reduction to $\mathrm{Cr}(\mathrm{I})$ in aromatic solvents. ${ }^{10,20}$ The performed XAS measurements required long acquisition times, which could have prevented the observation of short-lived complexes present within the solution.

To improve the time resolution of XAS in homogeneous catalysis, we have developed a freeze-quench XAS methodology. ${ }^{21}$ This methodology has allowed us to identify $\mathrm{Cr}$ (II) complexes which are formed in the activation of a $\mathrm{Cr}-\{\mathrm{SNS}\}$ and $\mathrm{Cr}-\{\mathrm{PNP}\}$ ethene trimerization and tetramerization system, respectively. ${ }^{14,15}$ In this study, we have combined the freeze-quench XAS methodology with EPR and UV-vis measurements to follow the various stages of preparation of the industrially applied Chevron Phillips Chemical ethene trimerization catalyst. This combination of techniques has allowed us to observe various $\mathrm{Cr}(\mathrm{I})$ and $\mathrm{Cr}(\mathrm{II})$ complexes which have not been characterized previously in this industrially applied system. Catalytic tests allow us to exclude some of the observed $\mathrm{Cr}(\mathrm{I})$ and $\mathrm{Cr}$ (II) complexes as the active species in this system.

\section{RESULTS AND DISCUSSION}

2.1. Preparation of the Chromium Precursor. We started our study by preparing and characterizing the chromium precursor used by Chevron Phillips Chemical: chromium 2-ethylhexanoate. Chromium 2-ethylhexanoate is generally assumed to be mononuclear in nature with a general structure of $\mathrm{Cr}(2-\mathrm{EH})_{3}(2-\mathrm{EH}=2$-ethylhexanoate $)$ and is sold by various commercial suppliers as a complex dissolved in mineral oil. In patent and academic literature several protocols describe the preparation of $\mathrm{Cr}(2-\mathrm{EH})_{3} \cdot{ }^{22-25}$ The attempted synthesis of $\mathrm{Cr}(2-\mathrm{EH})_{3}$ from $\mathrm{CrCl}_{3} \cdot 6 \mathrm{H}_{2} \mathrm{O}$ and sodium 2ethylhexanoate in THF and methanol gives rise to an oily product. The color of the formed complex is affected by the choice of solvent (Figure S1). Mass spectrometry shows the formation of polynuclear chromium complexes (Figure S2S4). In a recent patent and literature publication by Chevron Phillips Chemical, it is shown that the absence of water is important to the form the mononuclear complex. ${ }^{23,26}$ Performing a synthesis under inert and anhydrous conditions in THF, using $\mathrm{CrCl}_{3}(\mathrm{THF})_{3}, \mathrm{NaH}$, and 2-ethylhexanoic acid, gives rise to an oily green product. Mass spectrometry does indeed show the formation of the mononuclear complex, but significant amounts of polynuclear products can also be identified (Figure S6). These findings led us to question the general formulation of the structure of $\mathrm{Cr}(2-\mathrm{EH})_{3}$.

In a recent publication, Jeon et al. describe the synthesis of a well-defined neutral chromium precursor with the general structure $\mathrm{Cr}(2-\mathrm{EH})_{2} \mathrm{OH}^{27}$ Via a slightly modified version of their synthetic methods (using heptane instead of mineral oil as reaction solvent, Scheme 4) we managed to obtain a pale

Scheme 4. Preparation of the Chromium Precursor $\left[\mathrm{Cr}_{3} \mathrm{O}(2-\mathrm{EH})_{6}\left(\mathrm{H}_{2} \mathrm{O}\right)_{3}\right] \mathrm{Cl}$
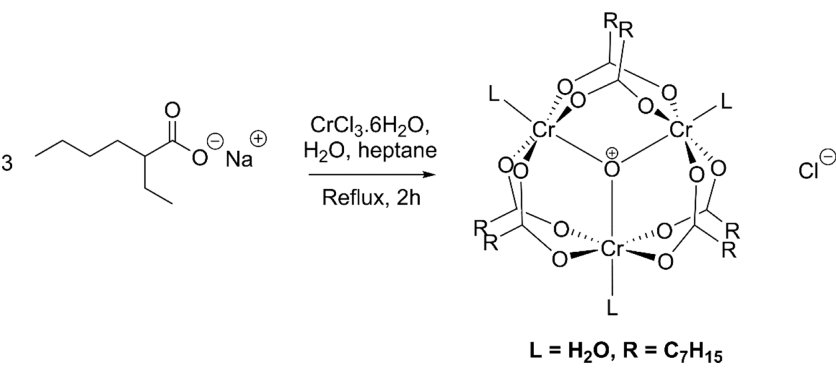

purple amorphous solid with a yield of 51\%. An unknown green impurity was removed by filtration of the complex over silica, which was not described in the original publication. The resulting complex (Figure S7) shows absorption peaks at $\lambda=$ $408 \mathrm{~nm}\left(\varepsilon=57 \mathrm{M}^{-1} \mathrm{~cm}^{-1}\right)$ and $\lambda=572 \mathrm{~nm}\left(\varepsilon=74 \mathrm{M}^{-1}\right.$ $\left.\mathrm{cm}^{-1}\right)$. These absorption peaks are in agreement with the results from Jeon et al. ( $\lambda=407 \mathrm{~nm}$ and $\lambda=572 \mathrm{~nm})$. In addition, the absorption bands observed in the ATR-IR spectrum of the product (Figure 1) matches closely with the FT-IR results obtained by Jeon et al., suggesting that a structurally similar complex is obtained. Based on their 


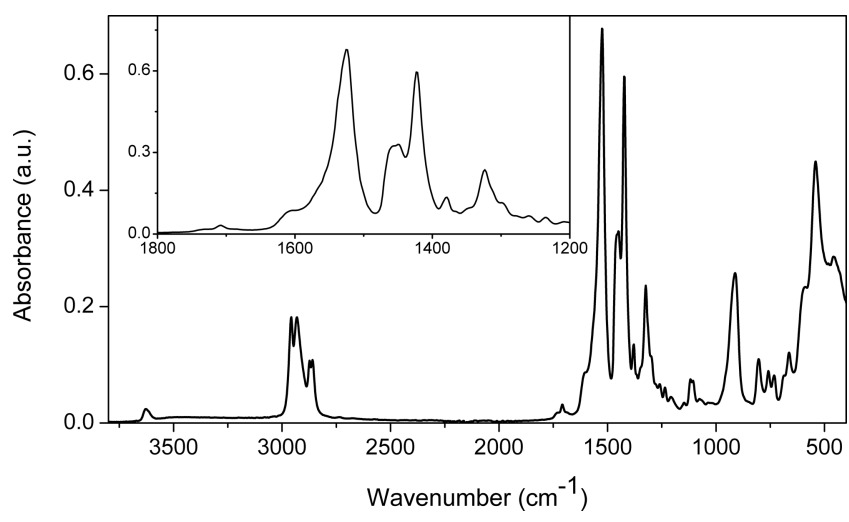

Figure 1. ATR-IR spectrum of $\left[\mathrm{Cr}_{3} \mathrm{O}(2-\mathrm{EH})_{6}\left(\mathrm{H}_{2} \mathrm{O}\right)_{3}\right] \mathrm{Cl}$. The inset of the figure shows an enlargement of the carboxylate stretches.

performed characterization (cryoscopy, IR and elemental analysis), the authors propose that the complex has the general structure $\mathrm{Cr}(2-\mathrm{EH})_{2} \mathrm{OH}$. Our characterization of this material is however not in line with this proposal.

Part of an ESI+ spectrum of the obtained chromium precursor is depicted in Figure 2a. Visible in the mass spectrum, is a $\left[\mathrm{Cr}_{3} \mathrm{O}(2-\mathrm{EH})_{6}\right]^{+}$fragment (found $m / z: 1030.47$, calculated $\mathrm{m} / \mathrm{z}: 1030.46)$. Additional fragments are observed containing acetonitrile, for example, $\left[\mathrm{Cr}_{3} \mathrm{O}(2-\mathrm{EH})_{6}(\mathrm{ACN})_{2}\right]^{+}$ (found $m / z: 1112.54$, calculated $m / z: 1112.51)$ and $\left[\mathrm{Cr}_{3} \mathrm{O}(2\right.$ $\left.\mathrm{EH})_{6}(\mathrm{ACN})_{3}\right]^{+}$(found $m / z: 1153.58$, calculated $\mathrm{m} / z$ : 1153.54). Formation of oxo-centered trinuclear chromium carboxylates is well-described in the literature, and crystal structures of related carboxylates have been investigated. ${ }^{28-30}$ Based on the observed fragmentation pattern (Figure 2), a trinuclear complex of the general structure $\left[\mathrm{Cr}_{3} \mathrm{O}(2\right.$ $\left.\mathrm{EH})_{6}\left(\mathrm{H}_{2} \mathrm{O}\right)_{3}\right] \mathrm{Cl}$ is proposed, where substitution of bound water for acetonitrile is observed in the ESI+ spectrum. Evidence of bound water can be found in the ESI+ spectrum, where fragments $\left[\mathrm{Cr}_{3} \mathrm{O}(2-\mathrm{EH})_{6}(\mathrm{OH})\right]^{+}$(found $m / z: 1047.52$, calculated $m / z: 1047.46)$ and $\left[\mathrm{Cr}_{3} \mathrm{O}(2-\mathrm{EH})_{6}(\mathrm{ACN})(\mathrm{OH})\right]^{+}$ (found $\mathrm{m} / z: 1088.52$, calculated $\mathrm{m} / z: 1088.49$ ) are observed to be caused by loss of a proton from bound water. In Figure $2 \mathrm{~b}$, the ESI+ spectrum is shown in the range of $450 \mathrm{~m} / z$ to $2000 \mathrm{~m} / z$. Minor other fragments are observed, but these cannot be linked to a molecular structure. Further confirmation of the ionic nature of the molecule is found in the elemental analysis (Calculated: C, 51.44; H, 8.63; Cl, 3.16; Cr 13.92. Found: C, 51.19; H, 8.90, Cl, 3.09; Cr 13.92), which provides confirmation of the chloride anion in the structure of the isolated complex.

The attenuated total reflection (ATR) infrared (IR) spectrum of the complex is shown in Figure 1; the inset shows an enlargement of the carboxylate stretches of $\left[\mathrm{Cr}_{3} \mathrm{O}(2\right.$ $\left.\mathrm{EH})_{6}\left(\mathrm{H}_{2} \mathrm{O}\right)_{3}\right] \mathrm{Cl}$. A stretch is observed at $\nu_{\mathrm{OH}}=3628 \mathrm{~cm}^{-1}$, which can be ascribed to the hydroxyl stretching vibration of water bound to the chromium complex. Small traces of free acid are visible $\left(\nu_{\mathrm{COOH}}=1707 \mathrm{~cm}^{-1}\right)$; these traces could not be removed from the complex even after several steps of washing with acetone. The carboxylate stretches are observed at $\nu_{\text {sym }}=1525 \mathrm{~cm}^{-1}$ and $\nu_{\text {asy }}=1423 \mathrm{~cm}^{-1}$. A small shoulder is observed for the symmetric carboxylate stretch; in this region, however, also $\mathrm{H}_{2} \mathrm{O}$ bending vibrations are to be expected. The carboxylate stretches deviate from what is typically observed in the literature for other chromium carboxylates (for chromium acetate: $\nu_{\text {sym }}=1620 \mathrm{~cm}^{-1}$ and $\left.\nu_{\text {asy }}=1450 \mathrm{~cm}^{-1}\right){ }^{31}$ One explanation for this difference could be the long aliphatic chains of chromium(III) 2-ethylhexanoate, promoting aggregation and causing a slight distortion of its molecular structure. In this regard, cobalt(II) 2-ethylhexanoate is known to aggregate and form reverse micelles in hydrocarbon solvents. ${ }^{32}$ Finally, a strong absorption band is observed around $\nu=540$ $\mathrm{cm}^{-1}$; this band can be ascribed to asymmetric stretching of the $\left[\mathrm{Cr}_{3} \mathrm{O}\right]$ core of the complex as is also observed for other oxo-centered chromium carboxylates. ${ }^{33}$

Additional evidence of the trinuclear structure of $\left[\mathrm{Cr}_{3} \mathrm{O}(2\right.$ $\left.\mathrm{EH})_{6}\left(\mathrm{H}_{2} \mathrm{O}\right)_{3}\right] \mathrm{Cl}$ is found in EPR spectroscopy. Magnetic

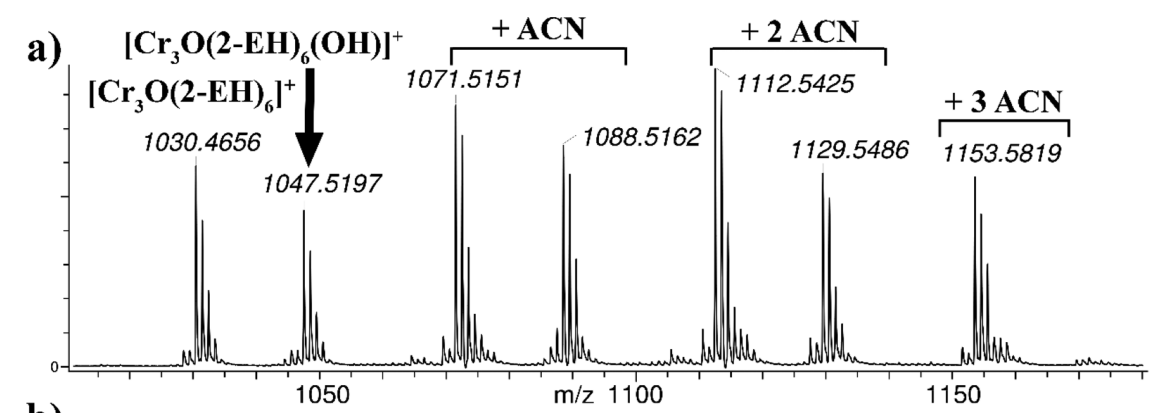

b)

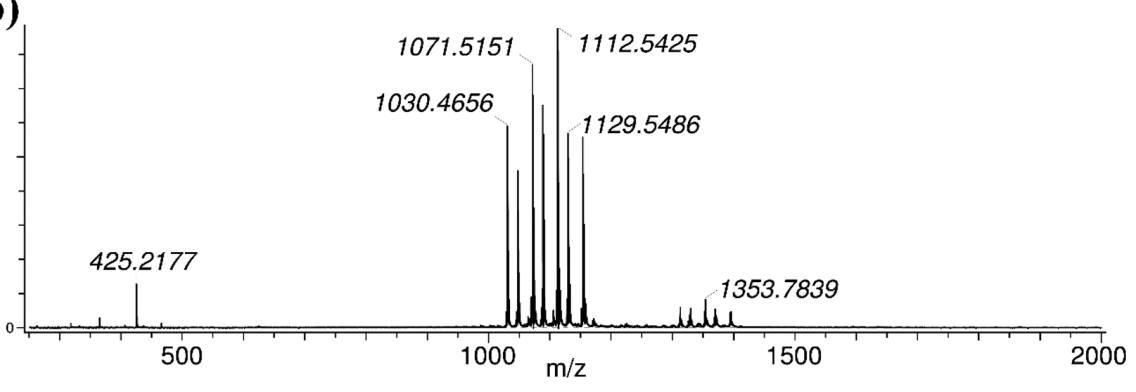

Figure 2. ESI+ mass spectrum of $\left[\mathrm{Cr}_{3} \mathrm{O}(2-\mathrm{EH})_{6}\left(\mathrm{H}_{2} \mathrm{O}\right)_{3}\right] \mathrm{Cl}$ showing (a) an enlargement of the fragments which are assigned to trinuclear chromium species and (b) an overview of all observed fragments up to $m / z=2000$. Text above fragmentation pattern is used to assign some of the observed species. 

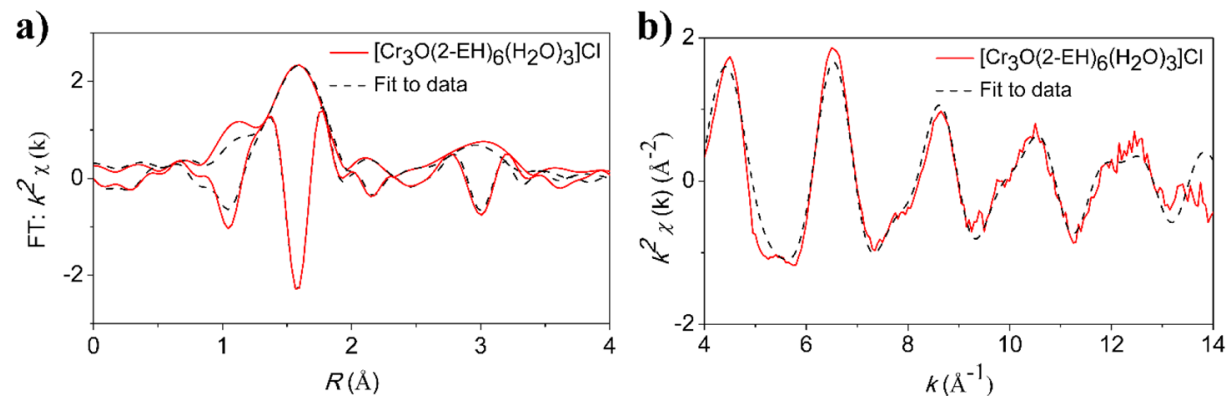

Figure 3. (a) Fourier transform of $k^{2}$-weighted $\mathrm{Cr}$ K-edge EXAFS data of $\left[\mathrm{Cr}_{3} \mathrm{O}(2-\mathrm{EH})_{6}\left(\mathrm{H}_{2} \mathrm{O}\right)_{3}\right] \mathrm{Cl}$ in cyclohexane $(10 \mathrm{mM})$ and $(\mathrm{b})$ the corresponding $k^{2}$-weighted experimental EXAFS oscillations. Shown in red is the experimental data and shown in black is the fit to the experimental data using the parameters shown in Table 1.

Table 1. Parameters That Were Used to Obtain a Fit for $\left[\mathrm{Cr}_{3} \mathrm{O}(2-\mathrm{EH})_{6}\left(\mathrm{H}_{2} \mathrm{O}\right)_{3}\right] \mathrm{Cl}$ in Cyclohexane $(10 \mathrm{mM})^{a}$

$\begin{array}{cllcr}\text { coordination shell } & N & \sigma^{2}\left(\AA^{2}\right) & d(\mathrm{Cr}-\mathrm{X})(\AA \AA \text { observed }) & d(\mathrm{Cr}-\mathrm{X})(\AA, \mathrm{DFT}) \\ \mathrm{Cr}-\mathrm{O} & 6.3(8) & 0.002(1) & 1.98(1) & 2.00(9) \\ \mathrm{Cr}-\mathrm{C} & 4 & 0.003(5) & 2.95(3) & 2.98(4) \\ \mathrm{Cr}-\mathrm{Cr} & 2 & 0.002(2) & 3.42(2) & 3.258(2)\end{array}$

${ }^{a}$ Bond lengths are compared to a DFT optimized structure of $\left[\mathrm{Cr}_{3} \mathrm{O}(2-\mathrm{EH})_{6}\left(\mathrm{H}_{2} \mathrm{O}\right)_{3}\right]^{+}$. General fitting parameters: $S_{0}{ }^{2}=0.92, E_{0}=7(2)$ eV, $\Delta k=$ $3.80-12.80 \AA^{-1}, \Delta R=1.20-3.42 \AA, R^{2}=0.017$, fitting was performed in R-space with a $k$-weighting of $k^{1}-k^{3}$. The DFT structure of $\left[\mathrm{Cr}_{3} \mathrm{O}(2\right.$ $\left.\mathrm{EH})_{6}\left(\mathrm{H}_{2} \mathrm{O}\right)_{3}\right]^{+}$was calculated without taking into account the anion. DFT calculated distances were calculated by averaging the distances to the metal centers of the various contributors contained within a shell. The standard deviation is given for both the experimental data and for the DFT calculated structure. Calculations are reported for the quartet state using BP86- $\mathrm{d}^{3} / \mathrm{TZP}$.

Table 2. Catalytic Tests Performed with $\left[\mathrm{Cr}_{3} \mathrm{O}(2-\mathrm{EH})_{6}\left(\mathrm{H}_{2} \mathrm{O}\right)_{3}\right] \mathrm{Cl}$ under 1 bar of $\mathrm{C}_{2} \mathrm{H}_{4}{ }^{a}$

\begin{tabular}{llccccc}
\multicolumn{1}{c}{ catalyst } & solvent & $\mathrm{Cr}(\mu \mathrm{mol})$ & $\mathrm{T}\left({ }^{\circ} \mathrm{C}\right)$ & $1-\mathrm{C}_{6}(\mathrm{mg})^{b}$ & $\mathrm{TOF}^{c}$ & $\mathrm{PE}^{b}(\mathrm{mg})$ \\
{$\left[\mathrm{Cr}_{3} \mathrm{O}(2-\mathrm{EH})_{6}\left(\mathrm{H}_{2} \mathrm{O}\right)_{3}\right] \mathrm{Cl}$} & toluene & 10 & $\mathrm{RT}^{d}$ & 5.8 & 7 & 3.2 \\
{$\left[\mathrm{Cr}_{3} \mathrm{O}(2-\mathrm{EH})_{6}\left(\mathrm{H}_{2} \mathrm{O}\right)_{3}\right] \mathrm{Cl}$} & toluene & 10 & 50 & 8.3 & 10 & 1.3 \\
{$\left[\mathrm{Cr}_{3} \mathrm{O}(2-\mathrm{EH})_{6}\left(\mathrm{H}_{2} \mathrm{O}\right)_{3}\right] \mathrm{Cl}$} & cyclohexane & 10 & $\mathrm{RT}$ & 54.6 & 65 & 2.3 \\
{$\left[\mathrm{Cr}_{3} \mathrm{O}(2-\mathrm{EH})_{6}\left(\mathrm{H}_{2} \mathrm{O}\right)_{3}\right] \mathrm{Cl}$} & cyclohexane & 10 & 50 & 115.5 & 137 & 2.5 \\
commercial source & toluene & 5 & 50 & 8.3 & 20 & 1.5 \\
commercial source & cyclohexane & 5 & 50 & 22.5 & 53
\end{tabular}

${ }^{a}$ Reaction volume: $10 \mathrm{~mL}$, reaction time: $60 \mathrm{~min}$, internal standard: mesitylene $(3 \mathrm{mg} / \mathrm{mL}$ reaction solvent), additional reagents used: DMP (3 equiv), $\mathrm{AlEt}_{3}$ (11 equiv), and $\mathrm{AlEt}_{2} \mathrm{Cl}$ ( 8 equiv). ${ }^{b}$ Amount of 1 -hexene was determined by GC. ${ }^{c} \mathrm{TOF}$ is defined as mole of 1 -hexene formed per mole chromium per hour. ${ }^{d} \mathrm{RT}=$ room temperature. Traces of decenes $(<1 \mathrm{~mol} \%)$ were observed in all performed experiments.

measurements of other trinuclear chromium carboxylates have revealed antiferromagnetic interactions between the chromium atoms in the $\left[\mathrm{Cr}_{3} \mathrm{O}\right]$ core. $^{28,30}$ These antiferromagnetic interactions gives rise to a doublet ground state and a thermally accessible quartet excited state. EPR measurements of $\left[\mathrm{Cr}_{3} \mathrm{O}(2-\mathrm{EH})_{6}\left(\mathrm{H}_{2} \mathrm{O}\right)_{3}\right] \mathrm{Cl}$ in toluene performed at variable temperatures are depicted in Figure S10. At $15 \mathrm{~K}$ and $40 \mathrm{~K}$ a broad resonance is observed with a g-value of $\sim 1.93$. This broad resonance is typical for an $S=3 / 2$ complex with a small zero field splitting. ${ }^{34}$ At $8 \mathrm{~K}$, an additional sharp resonance becomes visible with a g-value of $\sim 1.95$; the observation of this resonance at lower temperature is in line with population of the $S=1 / 2$ ground state.

In addition, the geometry of $\left[\mathrm{Cr}_{3} \mathrm{O}(2-\mathrm{EH})_{6}\left(\mathrm{H}_{2} \mathrm{O}\right)_{3}\right] \mathrm{Cl}$ in toluene was probed via $\mathrm{Cr} \mathrm{K}$-edge XAS. The $k^{2}$-weighted Fourier transform of the Cr K-edge EXAFS data for $\left[\mathrm{Cr}_{3} \mathrm{O}(2\right.$ $\left.\mathrm{EH})_{6}\left(\mathrm{H}_{2} \mathrm{O}\right)_{3}\right] \mathrm{Cl}$ is shown in Figure 3. The obtained EXAFS parameters and a comparison to a DF optimized structure is shown in Table 1. Three shells are used to obtain a fit for the data. The first shell is an oxygen shell containing 6.3(8) atoms at a distance of $1.98(1) \AA$. It is not possible to identify a separate oxygen shell for the mu-oxo $(1.881(3) \AA)$ or for bound water $(2.175(7) \AA)$ as the $\mathrm{Cr}-\mathrm{O}$ distances are too similar to be distinguished with our data quality. The second shell is a carbon shell containing four atoms at a distance of 2.95(3) A. This carbon shell is assigned to the carbons contained in the bridging carboxylates. The third shell is a chromium shell containing two atoms at a distance of 3.42(2) $\AA$ and is assigned to chromium atoms contained within the $\left[\mathrm{Cr}_{3} \mathrm{O}\right]$ core.

DFT calculations on the BP86- $\mathrm{d}^{3} / \mathrm{TZP}$ level were performed to compare experimental bond lengths to calculated bond lengths (see Table 1). This level of theory does not accurately predict a doublet ground state for the complex: the quartet spin state is favored over the doublet spin state. This is presumably due to pure density functionals such as BP86 favoring low spin states over high spin states. ${ }^{35}$ Nevertheless, only minor geometrical differences are observed between the two spin states, and the geometry of the quartet spin state is thus used to compare to the experimental data.

The experimental $\mathrm{Cr}-\mathrm{C}$ and $\mathrm{Cr}-\mathrm{O}$ bond lengths are in excellent agreement with the performed calculations and only minor differences $(\sim 0.03 \AA)$ are observed. A much larger deviation is however observed for the $\mathrm{Cr}-\mathrm{Cr}$ distance. Comparison of the DFT structure of $\left[\mathrm{Cr}_{3} \mathrm{O}(2\right.$ $\left.\mathrm{EH})_{6}\left(\mathrm{H}_{2} \mathrm{O}\right)_{3}\right]^{+}$with trinuclear chromium propionate shows that the calculated $\mathrm{Cr}-\mathrm{Cr}$ distance $(\sim 3.26 \AA)$ matches closely with the crystal structure $(\sim 3.27 \AA) .{ }^{36}$ This level of theory is 
Table 3. Selective Oligomerization Experiments Performed under 50 bar of $\mathrm{C}_{2} \mathrm{H}_{4}{ }^{a}$

\begin{tabular}{clcccc} 
catalyst & solvent & $\mathrm{Cr}(\mu \mathrm{mol})$ & $\mathrm{T}\left({ }^{\circ} \mathrm{C}\right)$ & $\mathrm{1}^{-\mathrm{C}_{6}(\mathrm{~g})^{b}}$ & $\mathrm{TOF}^{c}$ \\
{$\left[\mathrm{Cr}_{3} \mathrm{O}(2-\mathrm{EH})_{6}\left(\mathrm{H}_{2} \mathrm{O}\right)_{3}\right] \mathrm{Cl}$} & toluene & 50 & 90 & 3.95 & 1876 \\
{$\left[\mathrm{Cr}_{3} \mathrm{O}(2-\mathrm{EH})_{6}\left(\mathrm{H}_{2} \mathrm{O}\right)_{3}\right] \mathrm{Cl}$} & cyclohexane & 50 & 90 & 25.4 \\
\hline
\end{tabular}

${ }^{a}$ Reaction volume: $150 \mathrm{~mL}$, reaction time: $30 \mathrm{~m}$, internal standard: mesitylene $(3 \mathrm{mg} / \mathrm{mL}$ reaction solvent), additional reagents used: DMP (3 equiv), $\mathrm{AlEt}_{3}$ (11 equiv), and $\mathrm{AlEt}_{2} \mathrm{Cl}$ ( 8 equiv). ${ }^{b}$ Amount of 1 -hexene was determined by GC. ${ }^{c} \mathrm{TOF}$ is defined as mole of 1 -hexene formed per mole chromium per hour. Traces of decenes $(<1 \mathrm{~mol} \%)$ were observed in all performed experiments.

Scheme 5. Overview of the Reactivity Observed for the Reaction of DMP (3 equiv) with $\mathrm{AlEt}_{3}\left(11\right.$ equiv) and $\mathrm{AlEt} \mathrm{Cl}_{2}(8$ equiv) $)^{a}$

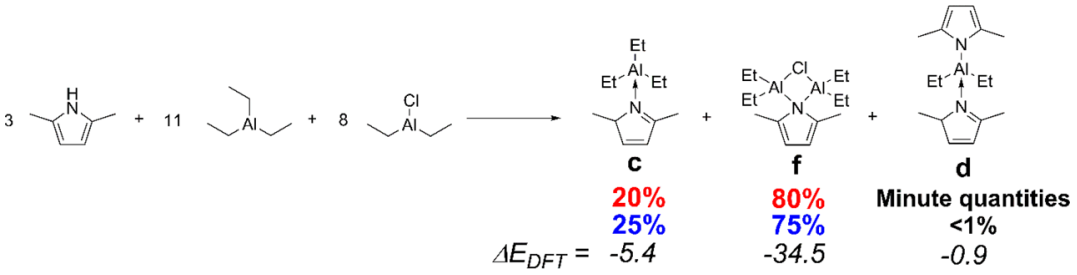

${ }^{a}$ Red depicts the observed quantity of the compound in toluene, blue depicts the observed quantity of the compound in cyclohexane and italics depicts the electronic energy $(\Delta E)$ of the given transformation. The amount of $\mathbf{d}$ was not quantified; it was found to be very minor compared with complex $\mathbf{c}$ and complex $\mathrm{f}$. Contents of the reaction mixture do not change any further after all DMP has been consumed. Resonances of $\mathbf{d}$ could not be observed in cyclohexane- $\mathrm{d}_{12}$, as it was not possible to cool the solution to $-40{ }^{\circ} \mathrm{C}$ due to the high melting point of the solvent.

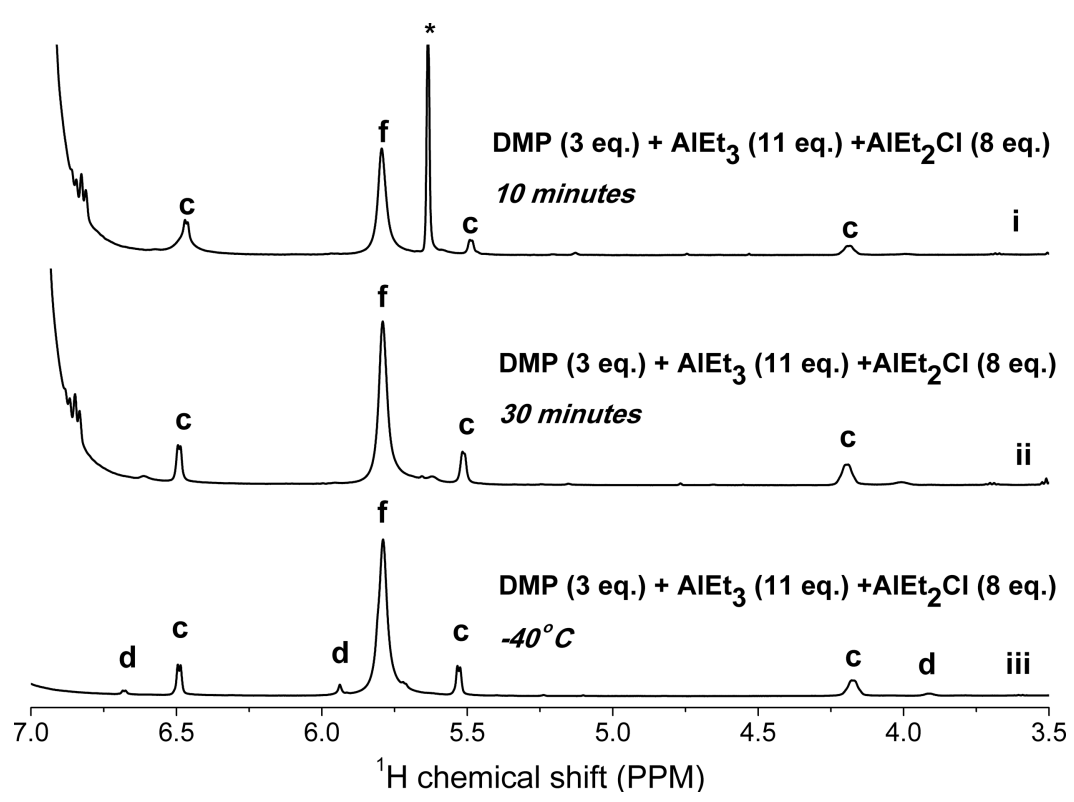

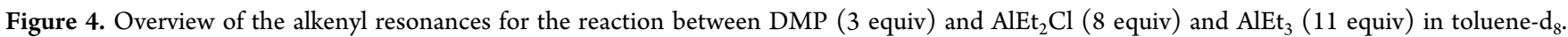
Shown in the figure are the ${ }^{1} \mathrm{H}$ NMR spectra of (i) the reaction measured after $10 \mathrm{~min}$ (ii) the reaction measured after 30 min and (iii) a reaction mixture cooled to $-40{ }^{\circ} \mathrm{C}$. Letters are used to assign resonances to species; the same coding is used as in Scheme 5. In addition, an asterisk is used to denote unreacted DMP.

thus sufficient to model the $\mathrm{Cr}-\mathrm{Cr}$ distance in trinuclear chromium carboxylates. Elongation of the $\mathrm{Cr}-\mathrm{Cr}$ distance is however observed in some trinuclear chromium carboxylates, that is, in fluorinated chromium carboxylates $(\sim 3.34 \AA)$ or in chromium carboxylates contained in metalorganic frameworks $(\sim 3.42 \AA$ and $\sim 3.48 \AA) .{ }^{37-39}$ The elongated $\mathrm{Cr}-\mathrm{Cr}$ distance is thus not unusual, its origin however remains unknown.

2.2. Catalytic Screening of $\left[\mathrm{Cr}_{3} \mathrm{O}(2-\mathrm{EH})_{6}\left(\mathrm{H}_{2} \mathrm{O}\right)_{3}\right] \mathrm{Cl}$. With an understanding of the structure of $\left[\mathrm{Cr}_{3} \mathrm{O}(2-\mathrm{EH})_{6}\left(\mathrm{H}_{2} \mathrm{O}\right)_{3}\right] \mathrm{Cl}$, the performance of the catalyst was assessed. Activation of the catalyst was achieved by reaction of $\left[\mathrm{Cr}_{3} \mathrm{O}(2-\mathrm{EH})_{6}\left(\mathrm{H}_{2} \mathrm{O}\right)_{3}\right] \mathrm{Cl}$ ( 1 equiv) with $\mathrm{AlEt}_{3}$ (11 equiv), $\mathrm{AlEt}_{2} \mathrm{Cl}$ ( 8 equiv), and $\mathrm{DMP}$ ( 3 equiv). ${ }^{40}$ Table 2 shows the catalytic tests performed under
1 bar of $\mathrm{C}_{2} \mathrm{H}_{4}$ in toluene and cyclohexane. ${ }^{41}$ The choice of solvent has a large effect on the performance of the catalyst. Performing the reaction in an aliphatic solvent leads to a 10fold increase in activity compared with an aromatic solvent. Reduced activity in aromatic solvents is also known from the patent literature: cyclohexane is often used as the reaction solvent. ${ }^{40}$ The origin of the reduced performance of the chromium-pyrrolyl system in aromatic solvents is still unclear. Suggestions have been made that toluene coordinates to a $\mathrm{Cr}(\mathrm{I})$ active species to form an arene complex and poisoning the catalyst in the process. $^{8}$ Similar deactivation pathways have been observed in related $\mathrm{Cr}-\{\mathrm{PNP}\}$ tri- and tetramerization systems. ${ }^{10,20,42}$ 

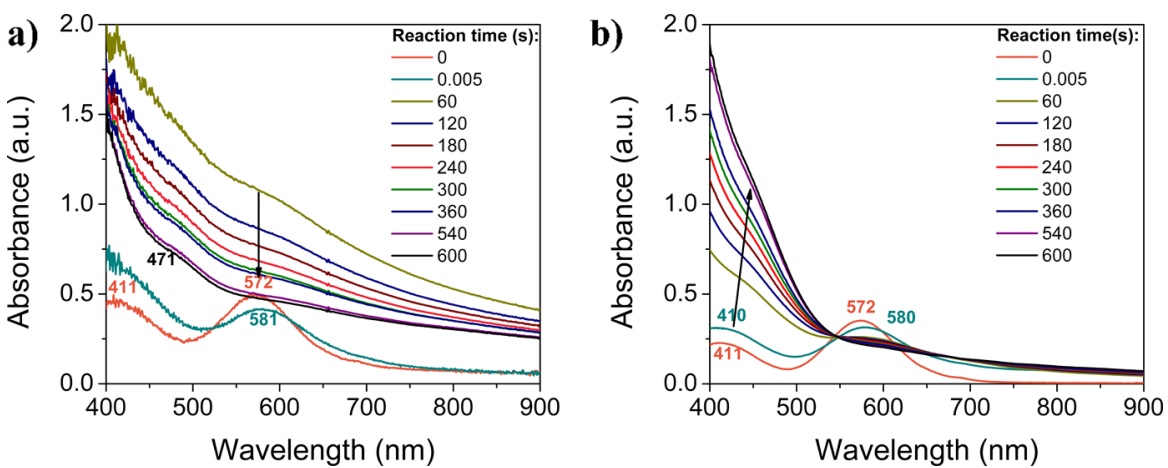

Figure 5. Activation of $\left[\mathrm{Cr}_{3} \mathrm{O}(2-\mathrm{EH})_{6}\left(\mathrm{H}_{2} \mathrm{O}\right)_{3}\right] \mathrm{Cl}$ (1 equiv, $\left.5 \mathrm{mM}\right)$ by $\mathrm{AlEt}_{3}$ (11 equiv), $\mathrm{AlEt}_{2} \mathrm{Cl}$ (8 equiv) and DMP (3 equiv) followed by stopped-flow UV-vis in (a) cyclohexane and (b) toluene. The concentration of $\mathrm{Cr}$ in the solution is $3.75 \mathrm{mM}$ in both experiments.

Increasing the reaction temperature from room temperature to $50{ }^{\circ} \mathrm{C}$ leads to a roughly 2 -fold increase of the activity of the catalyst in both aromatic and aliphatic solvents. Limited formation of polyethylene (PE) is observed in all performed reactions.

Only minor differences are observed between $\left[\mathrm{Cr}_{3} \mathrm{O}(2\right.$ $\left.\mathrm{EH})_{6}\left(\mathrm{H}_{2} \mathrm{O}\right)_{3}\right] \mathrm{Cl}$ and a commercial source of " $\mathrm{Cr}(2-\mathrm{EH})_{3}$ ". Ascribing differences between these two sources of chromium 2-ethylhexanoate is difficult due to the unknown nature of the commercial source (Strem). Mass spectrometry, elemental analysis, and XAS analysis of the commercial source however also indicate the presence of trinuclear, ionic complexes in the commercial source of chromium 2-ethylhexanoate (Supporting Information 2.4).

In Table 3, the results are shown for the reaction performed under 50 bar of $\mathrm{C}_{2} \mathrm{H}_{4}$ at $90{ }^{\circ} \mathrm{C}$. A 15 -fold increased activity is observed in cyclohexane with respect to toluene; roughly similar to what is also observed under 1 bar of $\mathrm{C}_{2} \mathrm{H}_{4}$. The activities observed are in close agreement with values reported in patent literature. ${ }^{40}$

2.3. Reaction of 2,5-Dimethylpyrrole with Triethylaluminum and Diethylaluminum Chloride. Before the catalyst is activated, DMP is first reacted with a mixture of $\mathrm{AlEt}_{3}$ and $\mathrm{AlEt}_{2} \mathrm{Cl}$. This solution is subsequently used to activate chromium 2-ethylhexanoate. ${ }^{40}$ The reaction between $\mathrm{AlEt}_{3}$ and $\mathrm{DMP}$ and $\mathrm{AlEt}_{2} \mathrm{Cl}$ and $\mathrm{DMP}$ was studied by Jeon et al., but so far no reports have been made of the reaction between a mixture of $\mathrm{AlEt}_{3}, \mathrm{AlEt}_{2} \mathrm{Cl}$, and $\mathrm{DMP} .{ }^{27}$ We therefore applied multinuclear NMR techniques and DFT to study the reaction between DMP (3 equiv) and $\mathrm{AlEt}_{3}$ (11 equiv) and $\mathrm{AlEt}_{2} \mathrm{Cl}$ ( 8 equiv) in both aromatic solvents and aliphatic solvents. In addition, we expanded on the structural assignment made by Jeon et al. for the reaction between $\mathrm{AlEt}_{3}$ (19 equiv) and DMP ( 3 equiv) and $\mathrm{AlEt}_{2} \mathrm{Cl}$ (19 equiv) and DMP (3 equiv); all of our results are summarized in Supporting Information 4.1 and 4.3 .

The reactions were performed by premixing $\mathrm{AlEt}_{3}$ (11 equiv) and $\mathrm{AlEt}_{2} \mathrm{Cl}$ ( 8 equiv) in an aromatic or aliphatic solvent. DMP (3 equiv) was added dropwise to this solution, and the solution was stirred for $10 \mathrm{~min}$. The solutions were briefly exposed to vacuum at $0{ }^{\circ} \mathrm{C}$, to remove any volatiles, after which deuterated solvents (toluene- $\mathrm{d}_{8}$ or cyclohexane$d_{12}$ ) were introduced. Three products can be identified that are formed during the reaction (Scheme 5 and Figure 4): adduct c and $\mathbf{d}$ and aminoalane $\mathbf{f}$. Ten minutes after the reagents are mixed, unreacted DMP resonances can still be identified (Figure 4i), but was found to be completely consumed after 30 min (Figure 4ii). In addition, a reaction mixture aged for 3 days shows no change in composition of the solution (Figure S38b). Only minor differences in composition of the solution were observed in toluene and cyclohexane.

The formation of $\mathrm{c}$ can be concluded on the basis of the ${ }^{1} \mathrm{H}$ NMR spectrum (Figure 4ii) and ${ }^{13} \mathrm{C}$ NMR spectrum (Figure S39): three novel resonances are observed caused by rearrangement of the double bond. In addition, two resonances for the methyl moieties are observed for $\mathrm{c}\left(\delta_{\mathrm{H}}=1.92\right.$ and 0.83 $\mathrm{ppm}$ ) due to desymmetrization of the pyrrolyl ring. DFT calculations show that the formation of this adduct is favorable $(\Delta E=-5.4 \mathrm{kcal} / \mathrm{mol}$; Supporting Information 5.4).

The resonances of $\mathbf{d}$ are very similar to the resonances observed for c. These resonances are broadened at room temperature, but can be observed at $-40{ }^{\circ} \mathrm{C}$. Interestingly, the aromatic proton resonances contained within the pyrrolyl moiety $\mathbf{d}$ can be observed as a separate resonance in the ${ }^{1} \mathrm{H}$ $\mathrm{NMR}$ and ${ }^{13} \mathrm{C}$ NMR spectrum $\left(\delta_{\mathrm{H}}=5.94 \mathrm{ppm}\right.$ and $\delta_{\mathrm{C}}=97.32$ $\mathrm{ppm}$ ) (Figure 4iii and Figure S39b). Only a very minor amount of the total amount of DMP present is converted into d $(<1 \%)$. DFT calculations show the formation of this adduct to be slightly favorable $(\Delta E=-0.9 \mathrm{kcal} / \mathrm{mol}$; Supporting Information 5.4).

The formation of aminoalane $\mathbf{f}$ can be concluded on the basis of the ${ }^{1} \mathrm{H}$ NMR and ${ }^{13} \mathrm{C}$ NMR spectra (Figure 4iii and Figure S39): a single resonance for the aromatic moiety is observed $\left(\delta_{\mathrm{H}}=5.72 \mathrm{ppm}\right.$ and $\left.\delta_{\mathrm{C}}=105.70 \mathrm{ppm}\right)$ and a single resonance for the methyl moiety is observed $\left(\delta_{\mathrm{H}}=2.24 \mathrm{ppm}\right.$ and $\delta_{\mathrm{C}}=16.80 \mathrm{ppm}$ ).

DFT calculations were employed to evaluate the relative electronic energy of various aminoalane dimers that can be formed in the presence of both $\mathrm{AlEt}_{3}$ and $\mathrm{AlEt}_{2} \mathrm{Cl}$ (see Supporting Information 5.4). The formation of aminoalane $\mathbf{f}$ is found to be most favored $(\Delta E=-34.5 \mathrm{kcal} / \mathrm{mol})$. Various other aminoalane dimers however do have very similar electronic energies compared to $\mathbf{f}$, and we considered the possibility of chemical exchange at room temperature. Splitting of the resonances of $\mathbf{f}$ is however not observed when the reaction mixture was cooled to $-40{ }^{\circ} \mathrm{C}$ (Figure 4iii), showing that the resonances of $\mathbf{f}$ arise from a single complex.

The observed aluminum complexes (see Scheme 5) will all be present when a chromium 2-ethylhexanoate solution is activated. In addition to these aluminum complexes, large excesses of $\mathrm{AlEt}_{3}$ and $\mathrm{AlEt}_{2} \mathrm{Cl}$ still are present after the reaction with DMP. The performed NMR experiments show that DMP reacts solely with $\mathrm{AlEt}_{3}$ (Supporting Information 4.1 and 4.3). Three equivalents of $\mathrm{AlEt}_{3}$ are thus required to deprotonate 

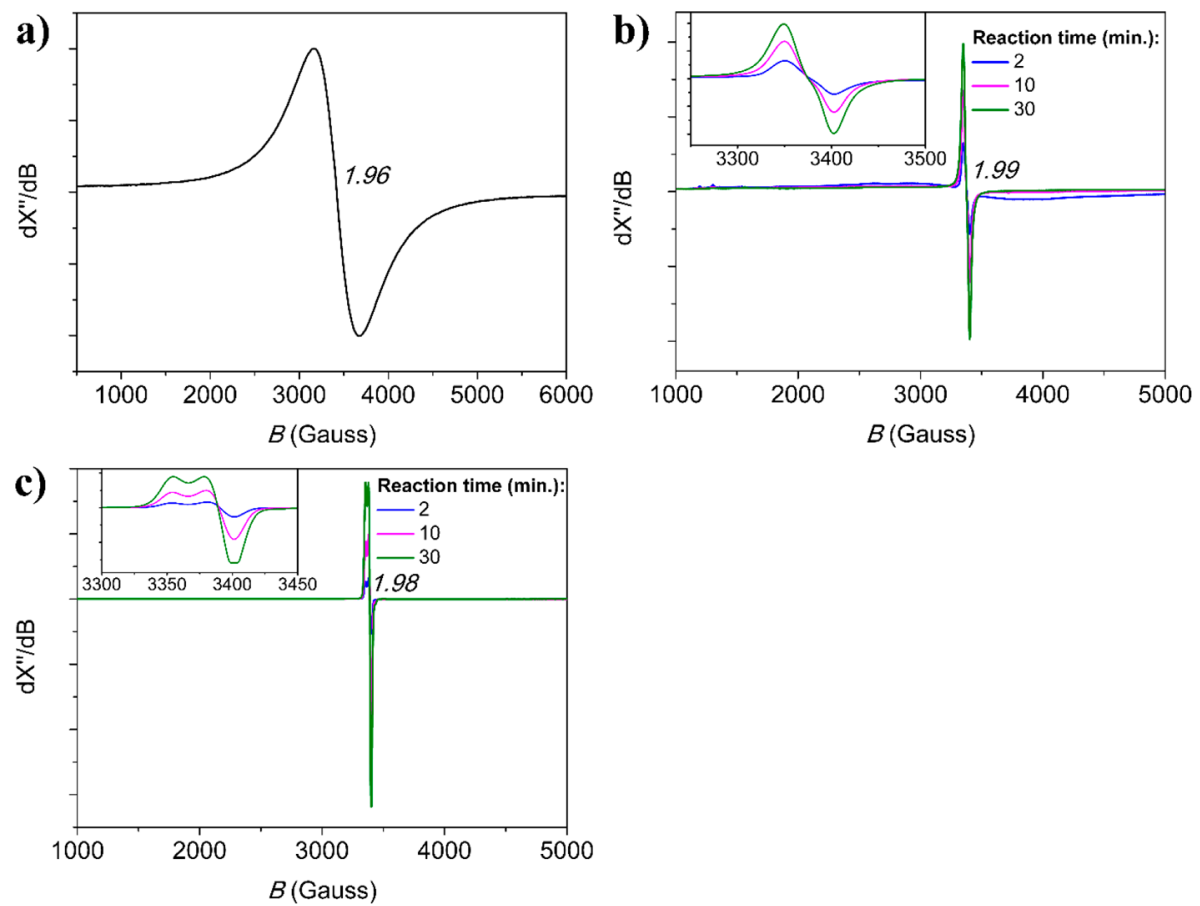

Figure 6. EPR spectra at $20 \mathrm{~K}$ of $(\mathrm{a})\left[\mathrm{Cr}_{3} \mathrm{O}(2-\mathrm{EH})_{6}\left(\mathrm{H}_{2} \mathrm{O}\right)_{3}\right] \mathrm{Cl}$ (toluene, $10 \mathrm{mM}$ in Cr), (b) $\left[\mathrm{Cr}_{3} \mathrm{O}(2-\mathrm{EH})_{6}\left(\mathrm{H}_{2} \mathrm{O}\right)_{3}(\mathrm{cyclohexane}, 8.46 \mathrm{mM}\right.$ in Cr) activated with $\mathrm{AlEt}_{3}$ (11 equiv), $\mathrm{AlEt}_{2} \mathrm{Cl}$ (8 equiv), and $\mathrm{DMP}$ (3 equiv), and (c) $\left[\mathrm{Cr}_{3} \mathrm{O}(2-\mathrm{EH})_{6}\left(\mathrm{H}_{2} \mathrm{O}\right)_{3}\right.$ (toluene, $9.09 \mathrm{mM}$ in $\mathrm{Cr}$ ) activated with $\mathrm{AlEt}_{3}$ (11 equiv), $\mathrm{AlEt}_{2} \mathrm{Cl}$ (8 equiv), and DMP (3 equiv). Reaction times are shown in the figure. The inset shows an enlargement of the observed $\mathrm{Cr}(\mathrm{I})$ resonances.

DMP prior to reaction with chromium, and the reaction mixture thus consists of the observed aluminum pyrrolyl complexes and eight equivalents of both $\mathrm{AlEt}_{3}$ and $\mathrm{AlEt}_{2} \mathrm{Cl}$.

2.4. Spectroscopic Investigation of the Activation of $\left[\mathrm{Cr}_{3} \mathrm{O}(2-\mathrm{EH})_{6}\left(\mathrm{H}_{2} \mathrm{O}\right)_{3}\right]$. With an understanding of the products formed in the reaction of DMP with $\mathrm{AlEt}_{3}$ and $\mathrm{AlEt}_{2} \mathrm{Cl}$, we set out to investigate the activation of $\left[\mathrm{Cr}_{3} \mathrm{O}(2-\mathrm{EH})_{6}\left(\mathrm{H}_{2} \mathrm{O}\right)_{3}\right] \mathrm{Cl}$. A variety of spectroscopic techniques were applied (EPR, XAS, and UV-vis) to probe both geometry and electronic structure of the activated metal center in both toluene and cyclohexane. Throughout each of the experiments reported below, we employed a stoichiometry of 1:3:11:8 with respect to $\mathrm{Cr}$, $\mathrm{DMP}, \mathrm{AlEt}_{3}$, and $\mathrm{AlEt}_{2} \mathrm{Cl}$. Activation of chromium was typically performed via premixing of $\mathrm{DMP}, \mathrm{AlEt}_{3}$, and $\mathrm{AlEt}_{2} \mathrm{Cl}$, after which $\left.\left[\mathrm{Cr}_{3} \mathrm{O}(2-\mathrm{EH})_{6}\right)\left(\mathrm{H}_{2} \mathrm{O}\right)_{3}\right] \mathrm{Cl}$ was added to this solution.

2.4.1. Activation of $\left[\mathrm{Cr}_{3} \mathrm{O}(2-\mathrm{EH})_{6}\left(\mathrm{H}_{2} \mathrm{O}\right)_{3}\right] \mathrm{Cl}$ Followed by Stopped-Flow UV-vis. The stopped-flow UV-vis spectra for the activation of $\left[\mathrm{Cr}_{3} \mathrm{O}(2-\mathrm{EH})_{6}\left(\mathrm{H}_{2} \mathrm{O}\right)_{3}\right] \mathrm{Cl}(1)$ in cyclohexane and toluene are presented in Figure 5. 1 shows two absorption bands at 411 and $572 \mathrm{~nm}$. Upon activation of 1 in cyclohexane, an immediate shift $(<5 \mathrm{~ms})$ in absorption bands is observed, and a novel band is observed at $580 \mathrm{~nm}$. Another absorption band is observed around $410 \mathrm{~nm}$, but could not be properly assigned as it overlaps with a rising charge-transfer (CT) band. These changes are accompanied by the solution immediately becoming turbid after activation. This increase in turbidity gives rise to a general increase of the absorption of the solution due to scattering of the formed particles (Figure 5a). Over time, disappearance of the absorption bands at 410 and 580 $\mathrm{nm}$ is observed, and a novel absorption band appears at 471 $\mathrm{nm}$. No other absorption bands can be distinguished, presumably due to overlap with the CT band.
After $10 \mathrm{~min}$, the solution becomes clear again, and the general absorption of the solution diminishes due to consumption of the formed particles (either via reaction or dissolution). The consumption rate of the particles was estimated by following the absorption of the background $(900 \mathrm{~nm})$ in time and follow approximate first-order reaction kinetics (Figure S47).

A very similar activation pathway is observed in toluene (Figure $5 \mathrm{~b}$ ). Immediately after activation $(<5 \mathrm{~ms})$ of $\mathbf{1}$, novel absorption bands are visible at 410 and $580 \mathrm{~nm}$. These absorption bands are similar to the ones observed in cyclohexane; however, in toluene, the solution remains clear after activation. On a time scale of $10 \mathrm{~min}$, disappearance of the absorption bands at 410 and $580 \mathrm{~nm}$ is observed and a rising CT band becomes visible. An additional absorption band is observed, which coincides with the rising CT band. It was not possible to accurately assign the wavelength of this absorption band. The observed changes in the UV-vis spectrum are accompanied by isosbestic points at 545 and $679 \mathrm{~nm}$. The changes can again be modeled via first-order reaction kinetics (Figure S48) and show a slower conversion in toluene compared to cyclohexane.

2.4.2. Activation of $\left[\mathrm{Cr}_{3} \mathrm{O}(2-\mathrm{EH})_{6}\left(\mathrm{H}_{2} \mathrm{O}\right)_{3}\right] \mathrm{Cl}$ Followed by $E P R$. EPR spectroscopy was applied to obtain information about the oxidation state of the metal after activation. The activation of this system in cyclohexane using EPR spectroscopy has already been studied in detail by Skobelev et al. In their study, the majority of the solution was found to be EPRsilent and a small fraction of a pyrrole-coordinated $\mathrm{Cr}(\mathrm{I})$ complex was observed. To build on their results, we investigated the activation in both cyclohexane and toluene to observe any possible differences in composition in an aromatic solvent and aliphatic solvent; our results are presented in Figure 6. The temperature-dependent EPR 

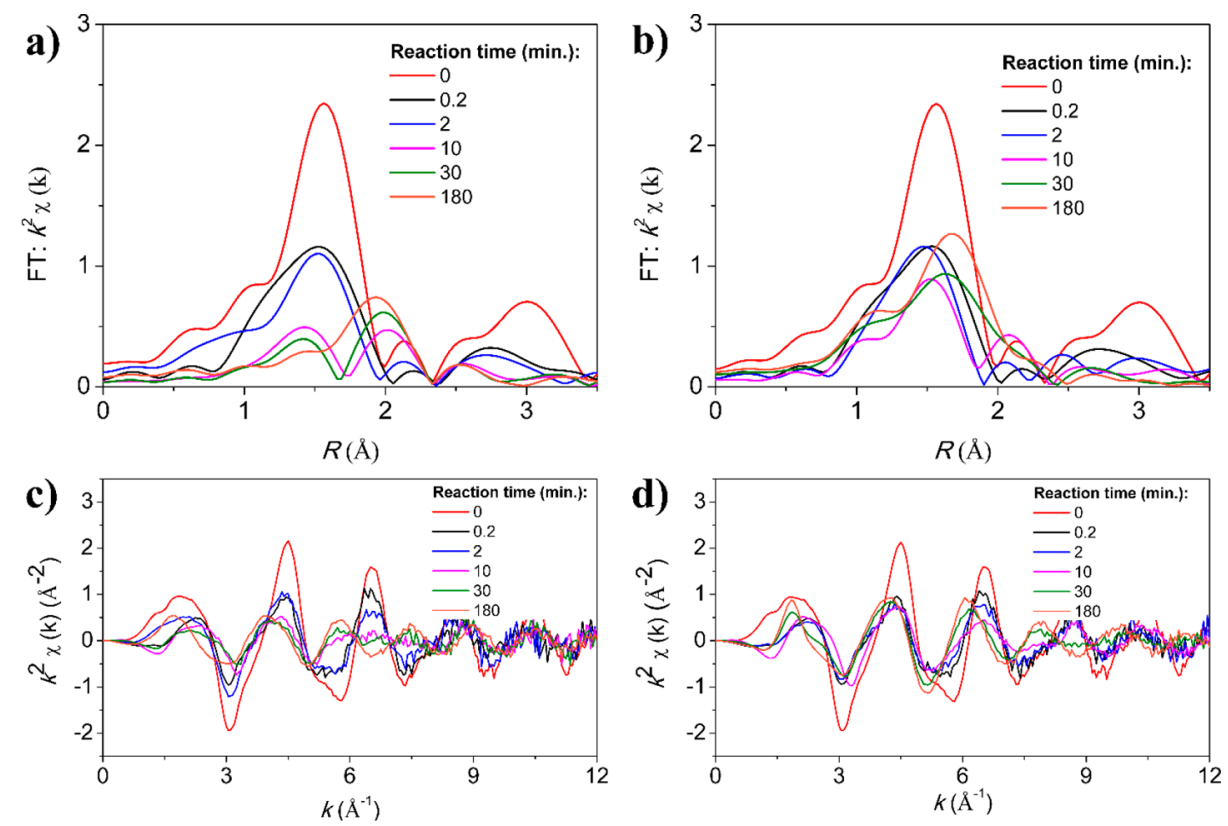

Figure 7. Fourier transform of $k^{2}$-weighted $\mathrm{Cr}$ K-edge EXAFS data for the activation of $\left[\mathrm{Cr}_{3} \mathrm{O}(2-\mathrm{EH})_{6}\left(\mathrm{H}_{2} \mathrm{O}\right)_{3}\right] \mathrm{Cl}$ by DMP $(3$ equiv), AlEt $3(11$ equiv), and $\mathrm{AlEt}_{2} \mathrm{Cl}$ (8 equiv) at various points in time in (a) cyclohexane (14.6 $\mathrm{mM}$ in $\mathrm{Cr}$ ) and (b) toluene $(16.7 \mathrm{mM}$ in $\mathrm{Cr})$ and the corresponding $k^{2}$-weighted EXAFS oscillations in (c) cyclohexane and (d) toluene. The $k$-range used in the Fourier transform for each data set was from 3.40 to $11.40 \AA^{-2}$ and a $k$-weighting of $k=2$ was employed.

spectra of 1 have already been discussed in detail (section 2.1) and will not be discussed here.

Activation of 1 in cyclohexane (Figure 6b) leads to rapid disappearance of its resonances: very minor amounts of 1 are observable after 2 min (Figure 6 and Figure S51). After 2 min a novel isotropic $\mathrm{Cr}(\mathrm{I})$ resonance is visible with a g-value of $\mathrm{g}_{\mathrm{x}, \mathrm{y}, \mathrm{z}}=1.988$. Quantitative EPR experiments performed at room temperature (Figure S49), using TEMPO as an external spin probe, show that $<1 \%$ of all chromium present is converted into this $\mathrm{Cr}(\mathrm{I})$ complex after an hour. The rest of the chromium is thus present as EPR-silent complexes (either as dinuclear $\mathrm{Cr}(\mathrm{I})$ complex or $\mathrm{Cr}(\mathrm{II})$ complex).

Skobelev et al.; ascribe the observed $\mathrm{Cr}(\mathrm{I})$ resonance to the formation of a $\mathrm{Cr}(\mathrm{I})$ pyrrolyl complex. ${ }^{9}$ The $\mathrm{Cr}(\mathrm{I})$ complex observed in this study might be different from the $\mathrm{Cr}(\mathrm{I})$ complex observed by Skobelev et al. as the symmetry of the line shape is different (current study: isotropic, previous study: axial). We only observed partially resolved superhyperfine splitting for the $\mathrm{Cr}(\mathrm{I})$ complex at room temperature (Figure S52) and we could not draw any conclusions on whether pyrrole is coordinated to the observed $\mathrm{Cr}(\mathrm{I})$ complex.

Relating UV-vis (Figure 6b) and EPR (Figure 5a) provides information about changes in the oxidation state of chromium over time. Quantitative EPR experiments show rapid reduction of 1 upon reaction with aluminum alkyl reagents. Within 2 min most of $\mathbf{1}$ is consumed and is transformed into EPR-silent complexes. These results suggest that the changes observed in the UV-vis on short time scales $(<2 \mathrm{~min})$ is due to a reduction of the catalyst via formation of an EPR-silent complex (2). UV-vis shows transformation of $\mathbf{2}$ into another complex (3); from EPR it can be concluded that 3 is also EPR-silent. EPR also shows the formation of a $\mathrm{Cr}(\mathrm{I})$ complex, which is present in low concentrations $(<1 \%)$. Due to the low concentration of this $\operatorname{Cr}(\mathrm{I})$ complex, it is unlikely that this complex is observable using UV-vis; these EPR resonances are thus assigned to another complex (4).
Similar observations are made when the activation of 1 is performed in toluene. The resonances arising from $\mathbf{1}$ disappear rapidly (Figure 6c and Figure S53), and an axial $\mathrm{Cr}(\mathrm{I})$ resonance appears with g-values of $\mathrm{g}_{\mathrm{x}, \mathrm{y}}=1.977$ and $\mathrm{g}_{z}=2.001$. The resonances in toluene are different compared to the ones observed in cyclohexane, as different g-values and symmetry of the line shapes are observed (isotropic and axial respectively); the resonances observed in toluene can thus be assigned to another $\mathrm{Cr}(\mathrm{I})$ complex (5) unrelated to 4 .

Quantitative EPR shows that the concentration of $\mathbf{5}$ is much higher compared to the concentration of 4 . Around $23 \%$ of the total chromium content of the solution is converted into 5 after $1 \mathrm{~h} .{ }^{43}$ No other resonances are observed after activation, showing that again a large fraction of EPR-silent chromium complexes are being formed. It is known that a $\mathrm{Cr}$ (III) source, an aluminum alkyl compound, and an aromatic solvent can be used to prepare cationic bis(arene) $\mathrm{Cr}(\mathrm{I})$ complexes. ${ }^{44}$ In addition, the formation of cationic bis(arene) $\mathrm{Cr}(\mathrm{I})$ complexes has been observed in other selective ethene oligomerization systems by Bercaw and co-workers and Brückner and coworkers. $^{10,20,42}$ Based on the much higher $\mathrm{Cr}(\mathrm{I})$ concentration in toluene compared to cyclohexane and the absence of $\mathbf{5}$ in cyclohexane, $\mathbf{5}$ is proposed to be a bis(tolyl) $\mathrm{Cr}(\mathrm{I})$ complex. We were not capable of resolving any superhyperfine splitting for 5 , even when the modulation amplitude was lowered from $4 \mathrm{G}$ to $1 \mathrm{G}$ (Figure S52). No conclusions can be made about the presence of $\mathbf{4}$ in toluene, as the resonances of $\mathbf{5}$ dominate the EPR spectrum.

Comparison of UV-vis and EPR results in toluene again provides information about the oxidation state of the catalyst after activation. EPR spectroscopy reveals immediate reduction of $\mathbf{1}$ and formation of $\mathbf{5}$ and large quantities of EPR-silent complexes. Very similar absorption bands in toluene and cyclohexane are observed immediately after activation of $\mathbf{1}$; these results thus also suggest formation of $\mathbf{2}$ in toluene. Over time, disappearance of the absorption bands of $\mathbf{2}$ is observed 
and a strong CT band is observed. The CT band likely originates from 5 as bis(arene) $\mathrm{Cr}(\mathrm{I})$ complexes have been shown to have strong CT bands in a similar region. ${ }^{45}$ Due to the intense CT band, it cannot be concluded whether 3 is also being formed in toluene.

2.4.3. Activation Followed by Freeze-Quench Cr K-Edge EXAFS. Although EPR and UV-vis spectroscopy provide important information about the oxidation state and kinetics of the metal during activation, no structural information is obtained. We therefore applied Cr K-edge XAS to follow the activation of $\mathbf{1}$ in toluene and cyclohexane.

An overview of the Cr K-edge EXAFS data in cyclohexane and toluene is presented in Figure 7 . The EXAFS fitting parameters are summarized in Table 4 and Table 5. The

Table 4. Structural Parameters Obtained from Fitting Cr Kedge EXAFS Data of the Activation in Cyclohexane ${ }^{a}$

\begin{tabular}{ccclc}
$\begin{array}{c}\text { reaction } \\
\text { time }\end{array}$ & $\begin{array}{c}\text { suggested } \\
\text { complex }\end{array}$ & \multicolumn{1}{c}{$\sigma^{2}\left(\AA^{2}\right)$} & coordination shell & $\begin{array}{c}d(\mathrm{Cr}-\mathrm{X}) \\
(\AA)\end{array}$ \\
$10 \mathrm{~s}$ & $2(100 \%)$ & $0.004(2)$ & $4.7(9) \mathrm{Cr}-\mathrm{O}$ & $1.97(2)$ \\
& & $0.007(6)$ & $4 \mathrm{Cr}-\mathrm{C}$ & $2.97(3)$ \\
$2 \mathrm{~min}$ & $2(100 \%)$ & $0.008(4)$ & $2 \mathrm{Cr}-\mathrm{Cr}$ & $3.36(4)$ \\
& & $0.004(1)$ & $3.9(4) \mathrm{Cr}-\mathrm{O}$ & $1.982(8)$ \\
& & $0.010(3)$ & $2 \mathrm{Cr}-\mathrm{Cr}$ & $3.36(2)$ \\
$10 \mathrm{~min}$ & $2(50 \%)$ & $0.0047(9)$ & $4 \mathrm{Cr}-\mathrm{O}$ & $1.93(2)$ \\
& & $0.010(3)$ & $2 \mathrm{Cr}-\mathrm{Cr}$ & $3.32(3)$ \\
& $3(50 \%)$ & $0.004(2)$ & $2 \mathrm{Cr}-\mathrm{Cl}$ & $2.34(1)$ \\
$30 \mathrm{~min}$ & $2(34 \% \pm 9 \%)$ & $0.003(4)$ & $4 \mathrm{Cr}-\mathrm{O}$ & $1.97(1)$ \\
& $3(66 \% \pm$ & $0.004(3)$ & $5 \mathrm{Cr}-\mathrm{C} / \mathrm{Cr}-\mathrm{N}$ & $2.31(2)$ \\
& $18 \%)$ & & & \\
& & $0.007(6)$ & $2 \mathrm{Cr}-\mathrm{Cl}$ & $2.38(2)$ \\
$3 \mathrm{~h}$ & $2(15 \%)$ & $0.005(5)$ & $4 \mathrm{Cr}-\mathrm{O}$ & $2.05(6)$ \\
& $3(85 \%)$ & $0.002(2)$ & $2 \mathrm{Cr}-\mathrm{Cl}$ & $2.36(3)$ \\
& & $0.002(3)$ & $5 \mathrm{Cr}-\mathrm{C} / \mathrm{Cr}-\mathrm{N}$ & $2.38(3)$ \\
& & $0.010(3)$ & $1 \mathrm{Cr}-\mathrm{Cr}$ & $2.94(4)$
\end{tabular}

${ }^{a}$ Samples $(14.6 \mathrm{mM})$ were prepared by freezing them in liquid nitrogen after a set reaction time. ${ }^{b}$ The actual coordination number in a given coordination shell is calculated by multiplying the coordination number with the relative abundance of the suggested complex. ${ }^{c} \mathrm{~A}$ restraint for the $\mathrm{Cr}-\mathrm{C}$ distance (range: $2.30-2.40 \AA$ ) was applied to model this shell; the absence of this restraint gave rise to an unrealistically long $\mathrm{Cr}-\mathrm{C}$ distance.

processed EXAFS data can be found in Supporting Information 8. The EXAFS analysis of $\mathbf{1}$ was already discussed in detail and was shown to be in line with the formation of a trinuclear $\mathrm{Cr}(\mathrm{III})$ carboxylate.

2.4.3.1. Activation of the Precursor in Cyclohexane. Addition of aluminum alkyl activators to 1 leads to immediate changes $(<10 \mathrm{~s})$ in the observed EXAFS, followed by slower changes over $3 \mathrm{~h}$.

The EPR and UV-vis results show that the majority species at short reaction times $(<2 \mathrm{~min})$ is EPR-silent complex 2 . This species is thus also being probed at short reaction times $(10 \mathrm{~s}$ and $2 \mathrm{~min}$ ) in the performed XAS experiments. EXAFS analysis of a reaction mixture frozen after 2 min (Figure S57 and Table S18) reveals identical coordination shells $(\mathrm{Cr}-\mathrm{O}$, $\mathrm{Cr}-\mathrm{C}$, and $\mathrm{Cr}-\mathrm{Cr}$ ) and bond distances as was observed for $\mathbf{1}$. These observations suggest that $\mathbf{2}$ has a very similar structure compared with $\mathbf{1}$. For the $\mathrm{Cr}-\mathrm{O}$ coordination shell, however, a reduction of the coordination number from $6.3(8)$ to $3.9(4)$ is
Table 5. Structural Parameters Obtained from Fitting Cr Kedge EXAFS Data of the Activation in Toluene ${ }^{a}$

\begin{tabular}{|c|c|c|c|c|}
\hline $\begin{array}{l}\text { reaction } \\
\text { time }\end{array}$ & $\begin{array}{l}\text { suggested } \\
\text { complex }\end{array}$ & $\sigma^{2}\left(\AA^{2}\right)$ & $\begin{array}{l}\text { coordination } \\
\text { shell }\end{array}$ & $d(\mathrm{Cr}-\mathrm{X})(\AA)$ \\
\hline \multirow[t]{3}{*}{$10 \mathrm{~s}$} & $2(100 \%)$ & $0.004(2)$ & $4.2(6) \mathrm{Cr}-\mathrm{O}$ & $1.97(1)$ \\
\hline & & $0.003(3)$ & $4 \mathrm{Cr}-\mathrm{C}$ & $2.98(2)$ \\
\hline & & $0.009(4)$ & $2 \mathrm{Cr}-\mathrm{Cr}$ & $3.35(3)$ \\
\hline \multirow[t]{3}{*}{$2 \mathrm{~min}$} & $2(100 \%)$ & $0.004(2)$ & $4.1(6) \mathrm{Cr}-\mathrm{O}$ & $1.96(1)$ \\
\hline & & $0.003(2)$ & $4 \mathrm{Cr}-\mathrm{C}$ & $2.97(2)$ \\
\hline & & $0.012(4)$ & $2 \mathrm{Cr}-\mathrm{Cr}$ & $3.32(3)$ \\
\hline \multirow[t]{4}{*}{$10 \mathrm{~min}$} & $\begin{array}{c}2(56 \% \pm \\
14 \%)\end{array}$ & $0.002(2)$ & $4 \mathrm{Cr}-\mathrm{O}$ & $1.98(1)$ \\
\hline & & $0.002(4)$ & $4 \mathrm{Cr}-\mathrm{C}$ & $2.97(3)$ \\
\hline & & $0.011(7)$ & $2 \mathrm{Cr}-\mathrm{Cr}$ & $3.35(5)$ \\
\hline & $\begin{array}{c}3(44 \% \pm \\
11 \%)\end{array}$ & $0.006(4)$ & $2 \mathrm{Cr}-\mathrm{Cl}$ & $2.41(2)$ \\
\hline \multirow[t]{4}{*}{$30 \min ^{b}$} & & $0.0075(8)$ & $4 \mathrm{Cr}-\mathrm{O} / \mathrm{Cr}-\mathrm{C}$ & $2.06(2)$ \\
\hline & & $0.006(5)$ & $2 \mathrm{Cr}-\mathrm{C}$ & $3.04(4)$ \\
\hline & & $0.011(6)$ & $1 \mathrm{Cr}-\mathrm{Cr}$ & $3.35(4)$ \\
\hline & & $0.008(3)$ & $0.8 \mathrm{Cr}-\mathrm{Cl}$ & $2.34(2)$ \\
\hline \multirow[t]{3}{*}{$3 h^{b}$} & & $0.005(2)$ & $5 \mathrm{Cr}-\mathrm{O} / \mathrm{Cr}-\mathrm{C}$ & $2.11(3)$ \\
\hline & & $0.006(6)$ & $1 \mathrm{Cr}-\mathrm{Cl}^{c}$ & $2.29(1)$ \\
\hline & & $0.004(4)$ & $0.5 \mathrm{Cr}-\mathrm{Cr}$ & $2.66(4)$ \\
\hline
\end{tabular}

${ }^{a}$ Samples $(16.7 \mathrm{mM})$ were prepared by freezing them in liquid nitrogen at a set reaction time. ${ }^{b}$ After $30 \mathrm{~min}$ and $3 \mathrm{~h}$ a mixture of various complex is present. It was not possible to assign the relative contribution to the EXAFS spectrum for each of these complexes due to the lack of parameters. The number depicted in the entry coordination shell is the actual parameter used in the EXAFS fit and was used to obtained the fit. ${ }^{c} \mathrm{~A}$ restraint for the $\mathrm{Cr}-\mathrm{Cl}$ distance (range: $2.30-2.42 \AA$ ) was applied to model this shell; the absence of this restraint gave rise to an unrealistically short $\mathrm{Cr}-\mathrm{Cl}$ distance.

observed. On the basis of these observations, we propose that 2 is a neutral polynuclear $\mathrm{Cr}$ (II) carboxylate species; using only the EXAFS data we cannot deduce the nuclearity of 2 .

DFT calculations were employed to explore the feasibility of formation of a neutral $\mathrm{Cr}$ (II) carboxylate from an ionic $\mathrm{Cr}$ (III) carboxylate (Supporting Information 8.1) in the presence of aluminum alkyl reagents. We envisioned that the bound water and central oxygen atom would easily be lost in the presence of aluminum alkyl reagents. Starting from trinuclear chromium acetate $(S=3 / 2)$, bound water is easily lost from chromium via reaction with $\operatorname{AlEt}_{3}(\Delta E=-97.3 \mathrm{kcal} / \mathrm{mol}$ and $\Delta G=$ $-170.0 \mathrm{kcal} / \mathrm{mol}$ ), giving rise to a five-coordinate $\mathrm{Cr}(\mathrm{III})$ carboxylate $(S=3 / 2)$. Subsequent alkylation and reduction of the $\mathrm{Cr}$ (III) carboxylate complex to form a trinuclear neutral $\mathrm{Cr}$ (II) carboxylate complex $(S=2)$ is also found to be very favorable $(\Delta E=-50.0 \mathrm{kcal} / \mathrm{mol}$ and $\Delta G=-61.4 \mathrm{kcal} / \mathrm{mol})$.

The EPR and UV-vis results show conversion of 2 to EPRsilent complex 3 at longer reaction times ( $>10 \mathrm{~min})$. Structural changes are evident from the $\mathrm{Cr}$ K-edge EXAFS results: at longer reaction times (10 $\mathrm{min}, 30 \mathrm{~min}$, and $3 \mathrm{~h}$ ), an additional coordination shell becomes visible (Figure $7 \mathrm{a}$ and Table 4).

Care had to be taken in the EXAFS analysis, as EPR and UV-vis spectroscopy indicates a mixture of (at least) three complexes $(\mathbf{2}, \mathbf{3}$, and $\mathbf{4})$. Because of the low concentration of $\mathbf{4}$, it is unlikely that this complex will significantly contribute to the EXAFS oscillations. We managed to successfully fit the EXAFS oscillations at longer reaction times $(10 \mathrm{~min}, 30 \mathrm{~min}$, and $3 \mathrm{~h}$ ) by assuming conversion of a polynuclear $\mathrm{Cr}$ (II) carboxylate (2) to a dinuclear Cr(II) pyrrolyl complex (3) (see Scheme 6). This structural assignment was obtained by first introducing coordination shells and optimizing the corre- 
Scheme 6. Incomplete Conversion of the Initially Formed $\mathrm{Cr}$ (II) Carboxylate Complex (2) to a Cr(II) Pyrrolyl Complex (3) ${ }^{a}$

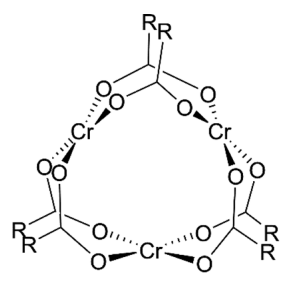

2

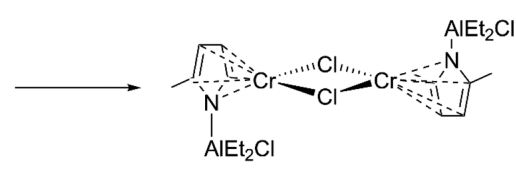

3
${ }^{a}$ It should be noted that the nuclearity of $\mathbf{2}$ is unknown and is drawn as trinuclear for illustrative purposes.

sponding coordination numbers and bond distances. Next, the obtained bond distances and coordination numbers were compared to crystal structures of $\mathrm{Cr}$ pyrrolyl complexes and $\mathrm{Cr}$ carboxylate complexes in the literature, and likely structures of the two observed complexes were proposed. Finally, an additional parameter was introduced and optimized to describe the relative concentration of the two observed complexes; this parameter is depicted in Table 4. Our findings for the EXAFS analysis of a reaction mixture frozen after $30 \mathrm{~min}$ are discussed below.

A total of three coordination shells are required to obtain a fit for the reaction mixture frozen after $30 \mathrm{~min}$. EXAFS analysis reveals that $66 \%$ is converted into 3 . The presence of 2 inside the reaction mixture can be concluded based on the presence of a $\mathrm{Cr}-\mathrm{O}$ coordination shell containing four atoms observed at a distance of 1.97(1) ^. A similar coordination shell was also observed for reaction mixtures frozen after $10 \mathrm{~s}$ and $2 \mathrm{~min}$ and is indicative of the presence of bridging carboxylates. The presence of 3 can be concluded on the basis of the presence of a $\mathrm{Cr}-\mathrm{C}$ and $\mathrm{Cr}-\mathrm{Cl}$ coordination shell. The $\mathrm{Cr}-\mathrm{C}$ shell is observed at a distance of 2.31(2) $\AA$ and contains five atoms. The $\mathrm{Cr}-\mathrm{Cl}$ shell is observed at a distance of 2.38(2) $\AA$ and contains two atoms. The observed distance and coordination number of the carbon shell is in line with $\pi$-coordination of the pyrrolyl ring to the metal center. ${ }^{46}$ In addition, the chloride distances are in line with bridging coordination of the chlorides. ${ }^{46}$ We thus assign 3 to the formation of a chlorobridged dinuclear $\mathrm{Cr}(\mathrm{II})$ pyrrolyl complex. The ability of $\mathrm{Cr}$ (II) pyrrolyl complexes to form dinuclear complexes is observed for other pyrrolyl ligands in the literature. ${ }^{8,46}$

Similar EXAFS fitting results are obtained for the sample frozen after $10 \mathrm{~min}$ (Figure S59 and Table S19) and $3 \mathrm{~h}$ (Figure S63 and Table S21). After $10 \mathrm{~min}, 50 \%$ is converted into 3 , and after $3 \mathrm{~h}, 85 \%$ is converted into 3 . Interestingly, for the sample frozen after $3 \mathrm{~h}$, it was possible to improve the fit by including a chromium shell containing one atom at a distance of 2.94(4) A. This chromium shell is assigned to 3 and provides further evidence for its dinuclear structure.

EXAFS can typically only probe the first coordination sphere of complexes in solution. We therefore applied DFT calculations on the BP86- $\mathrm{d}^{3} / \mathrm{TZP}$ level of theory to obtain more information about the geometry of 3 (Supporting Information 8.2). It is possible for a dinuclear $\mathrm{Cr}$ (II) pyrrolyl complexes to adopt either a planar structure (Scheme $7 \mathrm{~A}$ ) or a butterfly structure (Scheme $7 \mathrm{~B}$ ). ${ }^{46}$ Performing the calculations in the absence of any aluminum alkyl compounds shows that the butterfly geometry is slightly favored over the planar geometry $(\Delta E=1.1 \mathrm{kcal} / \mathrm{mol})$.
Scheme 7. Overview of the (A) Planar Geometry and (B) Butterfly Geometry, Which Can Be Adopted by Dinuclear Cr(II) Pyrrolyl Complexes ${ }^{a}$
A

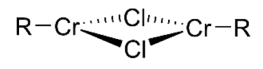

B

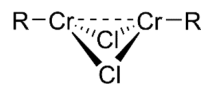

${ }^{a}$ The substituent for the two conformations that were taken into account in DFT calculations were $\mathrm{C}_{6} \mathrm{H}_{8} \mathrm{~N}, \mathrm{C}_{6} \mathrm{H}_{8} \mathrm{NAlEt}_{3}$, $\mathrm{C}_{6} \mathrm{H}_{8} \mathrm{NAlEtCl}(\mathrm{DMP})$, and $\mathrm{C}_{6} \mathrm{H}_{8} \mathrm{NAlEt}_{2} \mathrm{Cl}$.

It has been demonstrated that the lone pair of the nitrogen can form a dative bond with aluminum alkyl compounds present in the reaction mixture. ${ }^{8}$ We therefore took into account dative bond formation with several aluminum alkyl reagents $\left(\mathrm{AlEt}_{2} \mathrm{Cl}, \mathrm{AlEt}_{3}\right.$, and AlEtClDMP). The calculations indeed show that adduct formation is favored; formation of an adduct with $\mathrm{AlEt}_{2} \mathrm{Cl}$ is found to be most favored. In the presence of aluminum alkyl reagents, the planar geometry (Scheme 7A) becomes favored over the butterfly geometry (Scheme 7B). In the case of adduct formation with $\mathrm{AlEt}_{2} \mathrm{Cl}$, the difference between planar and butterfly geometry is found to be $\Delta E=6.7 \mathrm{kcal} / \mathrm{mol}$ in the singlet state. The $\mathrm{Cr}-\mathrm{Cl}$ distances (calculated: 2.36(3) $\AA$, experimental: 2.38(2) $\AA$ ), the Cr-C distances (calculated: 2.36(3) $\AA$, experimental: 2.38(3) $\AA$ ) and the $\mathrm{Cr}-\mathrm{Cr}$ distances (calculated: $2.87 \AA$, experimental: 2.94(3) $\AA$ ) obtained from the performed calculations match closely with the experimental values.

Interesting is the close resemblance between our proposed structure and self-activating catalysts isolated by Duchateau and Korobkov and co-workers, as depicted in Scheme 3., ${ }^{7,18}$ Structural resemblence between our proposed structure and these self-activating catalysts include a $\pi$-bound ligand and formation of a dative bond with aluminum. Two of these selfactivating catalysts are also dinuclear in nature. Closest in structural resemblence, is the self-activating $\mathrm{Cr}$ (II) catalyst which is depicted in Scheme 3b. In this complex, however, the bridging position is occupied by methyl substituents and the complex takes on a butterfly geometry.

2.4.3.2. Activation of the Precursor in Toluene. EXAFS analysis (Figure $7 \mathrm{~b}$ and Table 5) of $\mathbf{1}$ activated in toluene shows similar trends as compared to what is observed in cyclohexane on short time scales $(<10 \mathrm{~min})$. The mixtures frozen after $10 \mathrm{~s}$ (Figure S65 and Table S22) and $2 \mathrm{~min}$ (Figure S67 and Table S23) again show the presence of 2; similar coordination numbers and shells are observed as were required to perform the fit in cyclohexane.

EXAFS analysis of 1 activated after $10 \mathrm{~min}$ (Figure S69 and Table S24) in toluene shows the formation of a mixture of 2 and 3 with a relative contribution of $69 \% \pm 20 \%$ and $31 \% \pm$ $9 \%$ of the two complexes, respectively. It was possible to include a $\mathrm{Cr}-\mathrm{Cl}$ shell at a distance of $2.36(3) \AA$, which is indicative of the formation of 3 . It was not possible to include a separate $\mathrm{Cr}-\mathrm{C}$ shell for the pyrrolyl ring due to limitations in the quality of the data. Comparison of these relative contributions with the ones obtained in cyclohexane (Table 4) reveals slower conversion in toluene, in line with the observed slower kinetics in the performed stopped-flow UVvis experiments.

EXAFS analysis of $\mathbf{1}$ activated after $30 \mathrm{~min}$ (Figure S71 and Table S25) and $3 \mathrm{~h}$ (Figure S73 and Table S26) is highly complicated due to the overlap of the coordination shells of 

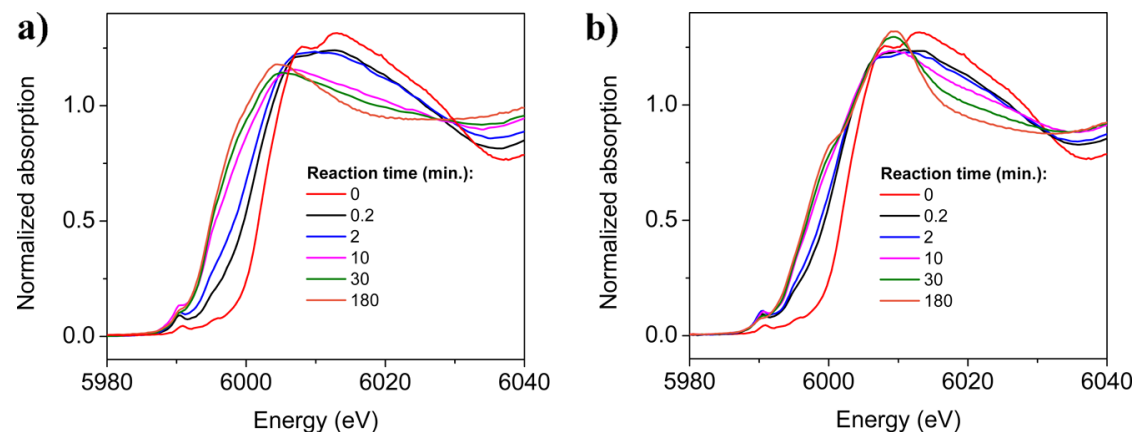

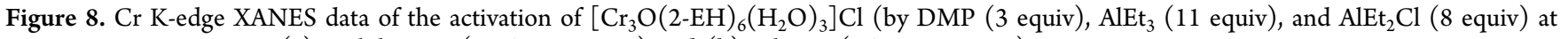
various points in time in (a) cyclohexane $(14.6 \mathrm{mM}$ in $\mathrm{Cr}$ ) and (b) toluene $(16.7 \mathrm{mM}$ in $\mathrm{Cr})$.

Scheme 8. Overview of the Various Species Formed upon Activation of 1 in the Presence of $\mathrm{AlEt}_{2} \mathrm{Cl}$ (8 equiv), $\mathrm{AlEt}_{3}(11$ equiv), and DMP (3 equiv)

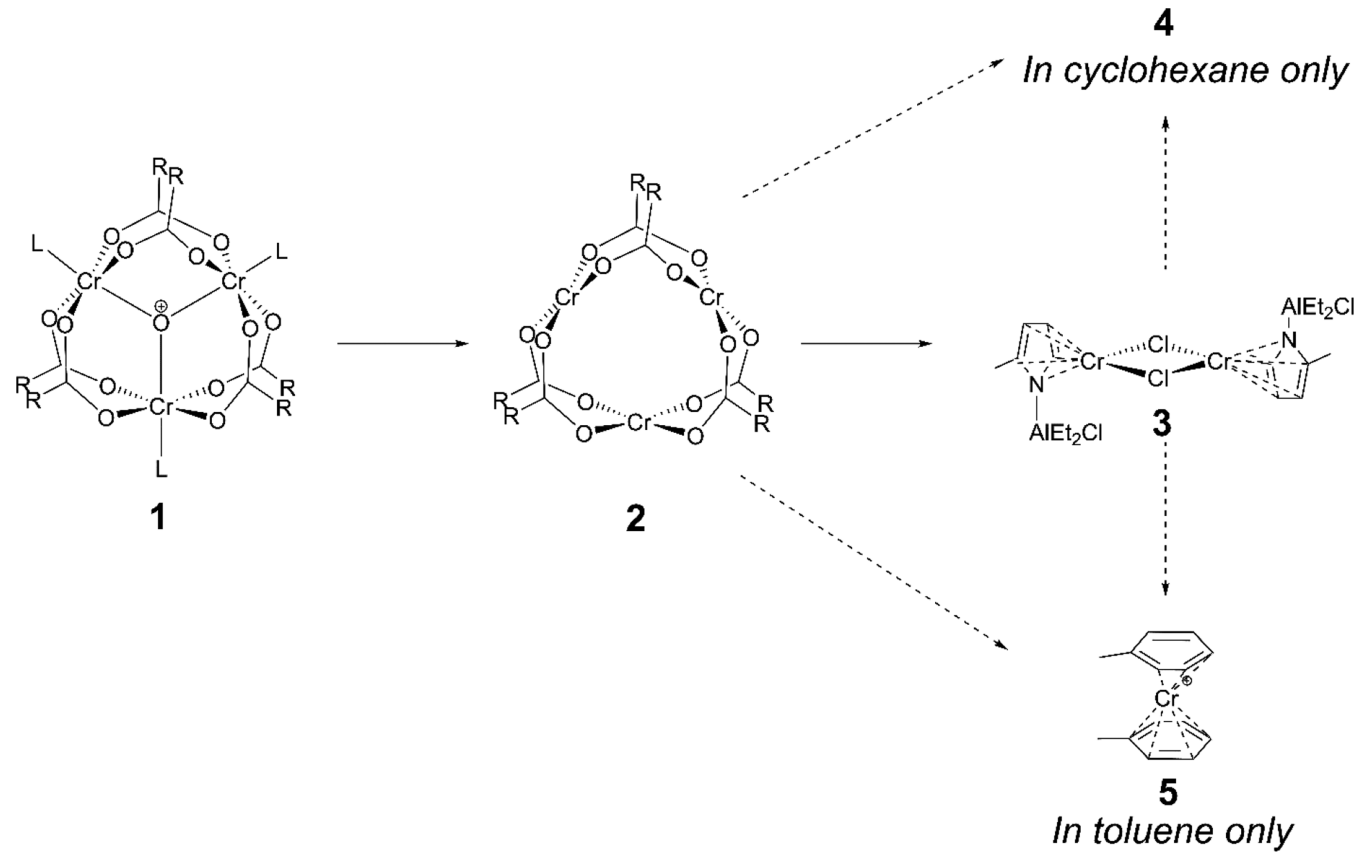

multiple species present. EPR and UV-vis spectroscopy show the presence of at least three complexes (2, 3, and 5). As a result, it was not possible to accurately determine the relative contributions of each of the species within the EXAFS spectra.

EXAFS analysis of $\mathbf{1}$ activated after $30 \mathrm{~min}$ suggest the presence of $\mathbf{2}, \mathbf{3}$, and $\mathbf{5}$. In the fit, a $\mathrm{Cr}-\mathrm{C}$ shell at a distance 3.04(4) $\AA$ and the $\mathrm{Cr}-\mathrm{Cr}$ shell at a distance of 3.35(4) $\AA$ had to be included, indicative of the presence of 2 . An additional $\mathrm{Cr}-\mathrm{C} / \mathrm{Cr}-\mathrm{O}$ shell was found at a distance of 2.06(2) $\AA$. The observed $\mathrm{Cr}-\mathrm{C} / \mathrm{Cr}-\mathrm{O}$ did not match the expected $\mathrm{Cr}-\mathrm{C}$ distance observed for $\left[\mathrm{Cr}\left(\mathrm{C}_{6} \mathrm{H}_{6}\right)_{2}\right] \mathrm{I}(2.13(4) \AA) .{ }^{47}$ Presumably this mismatch arises due to overlap of the $\mathrm{Cr}-\mathrm{O}$ shell of $\mathbf{2}$ and the $\mathrm{Cr}-\mathrm{C}$ shell of $\mathbf{5}$, causing an average to be observed. Finally, the presence of 3 can be concluded based on the observed $\mathrm{Cr}-$ $\mathrm{Cl}$ shell at a distance of 2.34(2) $\AA$. It was not possible to include a separate shell for the $\mathrm{Cr}-\mathrm{C}$ shell of the pyrrolyl ring.

After 3 h, presumably 2 is mostly consumed as it was not possible to include a $\mathrm{Cr}-\mathrm{C}$ shell or a $\mathrm{Cr}-\mathrm{Cr}$ shell for 2 . The presence of 5 can be concluded on the basis of the observed $\mathrm{Cr}-\mathrm{C}$ shell at a distance of 2.12(2) $\AA$ and was found to match closely with the expected $\mathrm{Cr}-\mathrm{C}$ distance (2.13(4) $\AA$ ). ${ }^{47}$ Finally, the presence of 3 can be concluded based on the observation of a $\mathrm{Cr}-\mathrm{Cl}$ shell at a distance of 2.33(1) $\AA$. To come to a successful fit, an additional $\mathrm{Cr}-\mathrm{Cr}$ shell at a distance of 2.69(5) A had to be included. Interestingly, the observed $\mathrm{Cr}-\mathrm{Cr}$ distance is shorter in toluene compared to cyclohexane (2.94(3) $\AA$ ); these results suggest that the choice of solvent might have an influence on the geometry of 3 .

2.4.4. Activation Followed by Freeze-Quench Cr K-Edge $X A N E S$. The observed $\mathrm{Cr}$ K-edge XANES data in cyclohexane and toluene are depicted in Figure 8a,b. In cyclohexane, 1 shows an absorption edge at $6001.7 \mathrm{eV}$. Activation of 1 leads to an immediate shift in absorption edge to $6000.9 \mathrm{eV}$. In addition to these changes, the whiteline intensity decreases and the intensity of the pre-edge feature increases. Over time, the position of the edge changes further and is $5994.1 \mathrm{eV}$ after 30 min. These additional changes are accompanied by a further decrease in the whiteline intensity and a further increase in the intensity of the pre-edge features. In addition, isosbestic points are observed at 6004.9 and $6029.0 \mathrm{eV}$. In toluene similar trends are observed, but these changes occur more slowly, in line with the slower kinetics observed in the stopped-flow UV-vis measurements. Additional features also appear after longer reaction times $(>10 \mathrm{~min})$, possibly due to the presence of 
bis(tolyl) $\mathrm{Cr}(\mathrm{I})$ complexes. These features were found to match closely with a known reference of $\left[\mathrm{Cr}\left(\mathrm{C}_{6} \mathrm{H}_{6}\right)_{2}\right] \mathrm{I}$ (Figure S75).

Unfortunately, we were unsuccessful in simulating the observed changes using the ab initio self-consistent field, real space, full multiple scattering methodology implemented in FEFF 9.0. ${ }^{48}$ Comparison of an experimental and calculated spectrum of a known standard, $\left[\mathrm{Cr}\left(\mathrm{C}_{6} \mathrm{H}_{6}\right)_{2}\right] \mathrm{I}$ (Figure S75), shows large discrepancies between the calculated and observed edge position and shape. Likely FEFF9.0 cannot be applied to model spectra of $\pi$-bound ligands. The observed trends can however be rationalized. Upon activation of $\mathbf{1}$, an immediate edge shift to lower energies is observed. This shift in edge position is in line with the reduction of complex $\mathbf{1}$ to form complex 2. Over time, the position of the edge shifts even further by more than $6 \mathrm{eV}$. FEFF9 calculations performed on the $\mathrm{Cr}$-\{SNS $\}$ show that substitution of chlorides into a complex can lead to an edge shift toward lower energies. ${ }^{14}$ The observed edge shift to lower energies over time can thus be understood to arise from substitution of carboxylates by chlorides in the conversion of 2 to 3 .

2.5. Correlation of Spectroscopic Data and Catalytic Data. The various observed species are summarized in Scheme 8. The concentration of the complexes formed vary over time and complicate the identification of the complex which is responsible for the generation of the active species. Upon activation of $\mathbf{1}$ immediate conversion to $\mathbf{2}$ is observed. Over longer time scales $(>10 \mathrm{~min})$, the concentration of 2 diminishes and $\mathbf{3}$ is formed. The conversion of $\mathbf{2}$ to $\mathbf{3}$ proceeds more slowly in toluene compared to cyclohexane, as is observed by both stopped-flow UV-vis and Cr K-edge XAS. In addition to the formation of 3 , also the formation of 4 is observed in cyclohexane and $\mathbf{5}$ is observed in toluene. The structure of $\mathbf{4}$ remains unknown. Using quantitative EPR it is possible to accurately determine the amount of $4(<1 \%$ after an hour) and 5 ( $\sim 23 \%$ after an hour). The relative concentration of 2 and 3 over time can be determined using the Cr K-edge EXAFS data, but the error margin is relatively high.

The catalyst is active in both cyclohexane and toluene (Table 2), indicating that the active species is generated in both solvents. This allows us to exclude $\mathbf{5}$ as a candidate for the active species as it is exclusively formed in toluene. The reduced performance of the catalyst in toluene suggests that formation of bis(tolyl)Cr(I) complexes leads to diminished performance of the catalyst.

The concentration of $\mathbf{2}, \mathbf{3}$, and $\mathbf{4}$ is time-dependent: over time, $\mathbf{2}$ is consumed, and $\mathbf{3}$ and $\mathbf{4}$ are formed. A catalytic experiment was performed where the turnover number was followed as a function of time for a catalyst prepared via in situ activation and a catalyst aged for 3 and $21 \mathrm{~h}$; the results are depicted in Figure S76. These experiments were performed under 1 bar of ethene at room temperature. Very limited dependency of the performance of the catalyst on the aging time is observed.

This allows us to exclude $\mathbf{2}$ as a candidate for the active species, as the concentration of $\mathbf{2}$ will be very low after aging the catalytic system for $21 \mathrm{~h}$. This also makes 3 to be less likely for the active species, as the concentration of 3 shows a large variation over time; low initial productivity would be expected for the catalyst prepared via in situ activation. The aging behavior makes 4 a more likely candidate for the generation of the active species, as the concentration of $\mathbf{4}$ varies very little over time (Figure S49). Nevertheless, we cannot completely exclude 3 , as it is present during all performed catalytic tests.
Alternatively, 3 and 4 could possibly both not participate in catalysis and catalysis might be performed by a minority, unobservable chromium complex. Similar suggestions have been made by Bercaw and co-workers in the spectroscopic investigation of a $\mathrm{Cr}-\{\mathrm{PNP}\}$ trimerization system. ${ }^{42}$

Additionally, the performed spectroscopic experiments have not been done in the presence of ethene. While the catalytic system is active under 1 bar of ethene, the catalytic system might undergo further changes in the presence of ethene. For example, Korobkov and co-workers have suggested heterolytic dissocation of a dinuclear tetramethylpyrrole $\mathrm{Cr}$ (II) complex (Scheme $3 b$ ) to be the pathway via which an active $\mathrm{Cr}(\mathrm{I})$ species is generated. ${ }^{8}$ Future spectroscopic experiments in the presence of ethene are underway to gain more insight into any additional changes the catalytic system undergoes in the presence of ethene.

\section{CONCLUSIONS}

In this study, chromium complexes were identified which are formed in the activation of the Chevron Phillips Chemical trimerization system under conditions applied in industry. The obtained results show a complicated pathway of activation in which multiple species are being formed. The precursor, an ionic trinuclear $\mathrm{Cr}$ (III) carboxylate, is initially reduced by the aluminum alkyl compounds to a polynuclear $\mathrm{Cr}$ (II) carboxylate. Over time, a novel chloro-bridged dinuclear $\mathrm{Cr}$ (II) pyrrolyl complex is formed.

In addition to the formation of $\mathrm{Cr}$ (II) complexes, also the formation of $\mathrm{Cr}(\mathrm{I})$ complexes is observed. In cyclohexane, only a small fraction $(<1 \%)$ is converted to an unknown $\operatorname{Cr}(\mathrm{I})$ species. In toluene, the formation of bis(tolyl)chromium(I) species is observed; a much larger fraction of the chromium content is found to be in the $\operatorname{Cr}(\mathrm{I})$ state $(\sim 23 \%)$. On the basis of the reduced performance of the catalyst in toluene, it is suggested that formation of $\mathrm{Cr}(\mathrm{I})$ complexes deactivates the catalyst.

No conclusions can be made regarding the actual active species. Catalytic tests allow to exclude the bis(tolyl)chromium(I) species and polynuclear $\mathrm{Cr}(\mathrm{II})$ carboxylate. These tests however do not exclude the dinuclear $\mathrm{Cr}$ (II) pyrrolyl complex, the $\mathrm{Cr}(\mathrm{I})$ complex observed in cyclohexane or yet another unobservable complex. In addition, the system might undergo further changes in the presence of ethene. Further spectroscopic studies in the presence of ethene are required to draw conclusions on the oxidation state of the active species.

\section{ASSOCIATED CONTENT}

\section{Supporting Information}

The Supporting Information is available free of charge on the ACS Publications website at DOI: 10.1021/acscatal.8b03414.

Supplementary data and experimental details for: synthesis and characterization of chromium 2-ethylhexanoate, reaction of 2,5-dimethylpyrrole with aluminum alkyls (NMR), kinetic and catalytic studies under $\mathrm{C}_{2} \mathrm{H}_{4}$ pressure, spectroscopic study of the activation of the metal (XAS, EPR and UV-vis), DFT calculations (PDF)

\section{AUTHOR INFORMATION}

\section{Corresponding Author}

*E-mail: moniek.tromp@rug.nl. 


\section{ORCID $\odot$}

David J. Martin: 0000-0002-3549-4202

Moniek Tromp: 0000-0002-7653-1639

\section{Present Address}

${ }^{\S}$ M.T.: Materials Chemistry, Zernike Institute for Advanced Materials, Faculty of Science and Engineering, University of Groningen, University of Groningen, Nijenborgh 4, 9747 AG Groningen, The Netherlands.

Notes

The authors declare no competing financial interest.

\section{ACKNOWLEDGMENTS}

The authors thank NWO for funding (VIDI grant 723.014.010 (to M.T., B.V., J.P.O., D.J.M.) and VENI grant 722.016.012 (to T.J.K.)). The authors thank the staff of the beamlines SuperXAS, Swiss Light Source (proposal number 20170855) in Villigen and B18, Diamond Light Source in Didcot (proposal number SP17599) for support and access to their facilities. The authors thank Michelle Hammerton for support during synchrotron measurements. The authors thank JanMeine Ernsting, Andreas Ehlers and Ed Zuidinga for NMR spectroscopy and mass spectrometry support. The authors thank Andreas Ehlers for support with the performed DFT calculations. The authors thank Bas de Bruin for aid and suggestions in the performed EPR experiments.

\section{REFERENCES}

(1) Al-Jarallah, A. M.; Anabtawi, J. A.; Siddiqui, M. A. B.; Aitani, A. M.; Al-Sa'doun, A. W. Ethylene dimerization and oligomerization to butene-1 and linear $\alpha$-olefins. Catal. Today 1992, 14 (1), 124.

(2) Britovsek, G. J. P.; Malinowski, R.; McGuinness, D. S.; Nobbs, J. D.; Tomov, A. K.; Wadsley, A. W.; Young, C. T. Ethylene Oligomerization beyond Schulz-Flory Distributions. ACS Catal. 2015, 5, 6922-6925.

(3) Peitz, S.; Aluri, B. R.; Peulecke, N.; Müller, B. H.; Wöhl, A.; Müller, W.; Al-Hazmi, M. H.; Mosa, F. M.; Rosenthal, U. An Alternative Mechanistic Concept for Homogeneous Selective Ethylene Oligomerization of Chromium-Based Catalysts: Binuclear Metallacycles as a Reason for 1-Octene Selectivity? Chem. - Eur. J. 2010, 16, 7670-7676.

(4) McGuinness, D. S.; Wasserscheid, P.; Keim, W.; Morgan, D.; Dixon, J. T.; Bollmann, A.; Maumela, H.; Hess, F.; Englert, U. First $\mathrm{Cr}$ (III)-SNS complexes and their use as highly efficient catalysts for the trimerization of ethylene to 1-hexene. J. Am. Chem. Soc. 2003, 125, $5272-5273$.

(5) Agapie, T. Selective ethylene oligomerization: Recent advances in chromium catalysis and mechanistic investigations. Coord. Chem. Rev. 2011, 255, 861-880.

(6) Agapie, T.; Labinger, J. A.; Bercaw, J. E. Mechanistic studies of olefin and alkyne trimerization with chromium catalysts: Deuterium labeling and studies of regiochemistry using a model chromacyclopentane complex. J. Am. Chem. Soc. 2007, 129, 14281-14295.

(7) Jabri, A.; Mason, C. B.; Sim, Y.; Gambarotta, S.; Burchell, T. J.; Duchateau, R. Isolation of single-component trimerization and polymerization chromium catalysts: The role of the metal oxidation state. Angew. Chem., Int. Ed. 2008, 47, 9717-9721.

(8) Vidyaratne, I.; Nikiforov, G. B.; Gorelsky, S. I.; Gambarotta, S.; Duchateau, R.; Korobkov, I. Isolation of a Self-Activating Ethylene Trimerization Catalyst. Angew. Chem., Int. Ed. 2009, 48, 6552-6556.

(9) Skobelev, I. Y.; Panchenko, V. N.; Lyakin, O. Y.; Bryliakov, K. P.; Zakharov, V. A.; Talsi, E. P. In Situ EPR Monitoring of Chromium Species Formed during Cr-Pyrrolyl Ethylene Trimerization Catalyst Formation. Organometallics 2010, 29, 2943-2950.

(10) Rabeah, J.; Bauer, M.; Baumann, W.; McConnell, A. E. C.; Gabrielli, W. F.; Webb, P. B.; Selent, D.; Brückner, A. Formation, Operation and Deactivation of Cr Catalysts in Ethylene Tetrameriza- tion Directly Assessed by Operando EPR and XAS. ACS Catal. 2013, 3, 95-102.

(11) McGuinness, D. S.; Brown, D. B.; Tooze, R. P.; Hess, F. M.; Dixon, J. T.; Slawin, A. M. Z. Ethylene trimerization with Cr-PNP and Cr-SNS complexes: Effect of ligand structure, metal oxidation state, and role of activator on catalysis. Organometallics 2006, 25, 36053610.

(12) Van Rensburg, W. J.; Grové, C.; Steynberg, J. P.; Stark, K. B.; Huyser, J. J.; Steynberg, P. J. A DFT Study toward the Mechanism of Chromium-Catalyzed Ethylene Trimerization. Organometallics 2004, 23, 1207-1222.

(13) McGuinness, D. S. Olefin oligomerization via metallacycles: Dimerization, trimerization, tetramerization, and beyond. Chem. Rev. 2011, 111, 2321-2341.

(14) Bartlett, S. A.; Moulin, J.; Tromp, M.; Reid, G.; Dent, A. J.; Cibin, G.; McGuinness, D. S.; Evans, J. Activation of $\left[\mathrm{CrCl}_{3}\{\mathrm{R}-\right.$ SN(H)S-R \}] Catalysts for Selective Trimerization of Ethene: A Freeze-Quench Cr K-Edge XAFS Study. ACS Catal. 2014, 4, 42014204.

(15) Bartlett, S. A.; Moulin, J.; Tromp, M.; Reid, G.; Dent, A. J.; Cibin, G.; McGuinness, D. S.; Evans, J. Activation of $\left[\mathrm{CrCl}_{3} \mathrm{PPh}_{2} \mathrm{~N}\right.$ $\left.\left.\left({ }^{\mathrm{i}} \mathrm{Pr}\right) \mathrm{PPh}_{2}\right\}\right]$ for the selective oligomerisation of ethene: a Cr K-edge XAFS study. Catal. Sci. Technol. 2016, 6, 6237-6246.

(16) Jabri, A.; Crewdson, P.; Gambarotta, S.; Korobkov, I.; Duchateau, R. Isolation of a cationic chromium(II) species in a catalytic system for ethylene tri- and tetramerization. Organometallics 2006, 25, 715-718.

(17) Reagan, W. K.; Freeman, J. W.; Conroy, B. K.; Pettijohn, T. M.; Benham, E. A. E. A. Process for the preparation of a catalyst for olefin polymerization. EP19930101111, 1994.

(18) Licciulli, S.; Albahily, K.; Fomitcheva, V.; Korobkov, I.; Gambarotta, S.; Duchateau, R. A Chromium Ethylidene Complex as a Potent Catalyst for Selective Ethylene Trimerization. Angew. Chem., Int. Ed. 2011, 50, 2346-2349.

(19) MacMillan, S. N.; Lancaster, K. M. X-ray Spectroscopic Interrogation of Transition-Metal-Mediated Homogeneous Catalysis: Primer and Case Studies. ACS Catal. 2017, 7, 1776-1791.

(20) Brückner, A.; Jabor, J. K.; McConnell, A. E. C.; Webb, P. B. Monitoring Structure and Valence State of Chromium Sites during Catalyst Formation and Ethylene Oligomerization by in Situ EPR Spectroscopy. Organometallics 2008, 27, 3849-3856.

(21) Bartlett, S. A.; Wells, P. P.; Nachtegaal, M.; Dent, A. J.; Cibin, G.; Reid, G.; Evans, J.; Tromp, M. Insights in the mechanism of selective olefin oligomerisation catalysis using stopped-flow freezequench techniques: A Mo K-edge QEXAFS study. J. Catal. 2011, 284, 247-258.

(22) Steele, R. B.; Katzakian, A.; Scigliano, J. J.; Hamel, E. E. Imide oxirane reactions. U.S. Patent US05487956, 1974.

(23) Sydora, O. L.; Knudsen, R. D.; Baralt, E. J. Preparation of transition metal carboxylates. U.S. Patent US13323191, 2011.

(24) Makhaev, V. D.; Petrova, L. A.; Alferov, K. A.; Belov, G. P. Mechanochemical synthesis of chromium tris(2-ethylhexanoate) and evaluation of its catalytic activity in the reaction of ethylene trimerization. Russ. J. Appl. Chem. 2013, 86, 1819-1824.

(25) Trudel, S.; Daryl Crozier, E.; Gordon, R. A.; Budnik, P. S.; Hill, R. H. X-ray absorption fine structure study of amorphous metal oxide thin films prepared by photochemical metalorganic deposition. J. Solid State Chem. 2011, 184, 1025-1035.

(26) Sydora, O. L.; Hart, R. T.; Eckert, N. A.; Martinez Baez, E.; Clark, A. E.; Benmore, C. J. A homoleptic chromium(iii) carboxylate. Dalt. Trans. 2018, 47, 4790-4793.

(27) Jeon, J. Y.; Park, D. S.; Lee, D. H.; Eo, S. C.; Park, S. Y.; Jeong, M. S.; Kang, Y. Y.; Lee, J.; Lee, B. Y. A chromium precursor for the Phillips ethylene trimerization catalyst: (2-ethylhexanoate) ${ }_{2} \mathrm{CrOH}$. Dalt. Trans. 2015, 44, 11004-11012.

(28) Vlachos, A.; Psycharis, V.; Raptopoulou, C. P.; Lalioti, N.; Sanakis, Y.; Diamantopoulos, G.; Fardis, M.; Karayanni, M.; Papavassiliou, G.; Terzis, A. A nearly symmetric trinuclear chromium(III) oxo carboxylate assembly: Preparation, molecular and crystal 
structure, and magnetic properties of $\left[\mathrm{Cr}_{3} \mathrm{O}\left(\mathrm{O}_{2} \mathrm{CPh}\right)_{6}(\mathrm{MeOH})_{3}\right]$ $\left(\mathrm{NO}_{3}\right) \cdot 2 \mathrm{MeOH}$. Inorg. Chim. Acta 2004, 357, 3162-3172.

(29) Figuerola, A.; Tangoulis, V.; Ribas, J.; Hartl, H.; Brüdgam, I.; Maestro, M.; Diaz, C. Synthesis, crystal structure, and magnetic studies of oxo-centered trinuclear chromium(III) complexes: $\left[\mathrm{Cr}_{3}\left(\mu_{3}\right.\right.$ $\left.\mathrm{O})\left(\mu_{2} \text { - } \mathrm{PhCOO}\right)_{6}\left(\mathrm{H}_{2} \mathrm{O}\right)_{3}\right] \mathrm{NO}_{3} \cdot 4 \mathrm{H}_{2} \mathrm{O} \cdot 2 \mathrm{CH}_{3} \mathrm{OH}$, a case of spin-frustrated system, and $\left[\mathrm{Cr}_{3}\left(\mu_{3}-\mathrm{O}\right)-\left(\mu_{2}-\mathrm{PhCOO}\right)_{2}\left(\mu_{2}-\right.\right.$ $\left.\left.\mathrm{OCH}_{2} \mathrm{CH}_{3}\right)_{2}(\text { bpy })_{2}(\mathrm{NCS})_{3}\right]$, a New Type of $\left[\mathrm{Cr}_{3} \mathrm{O}\right]$ Core. Inorg. Chem. 2007, 46, 11017-11024.

(30) Harton, A.; Nagi, M. K.; Glass, M. M.; Junk, P. C.; Atwood, J. L.; Vincent, J. B. Synthesis and characterization of symmetric and unsymmetric oxo-bridged trinuclear chromium benzoate complexes: Crystal and molecular structure of $\left[\mathrm{Cr}_{3} \mathrm{O}\left(\mathrm{O}_{2} \mathrm{CPh}\right)_{6}(\mathrm{py})_{3}\right] \mathrm{ClO}_{4}$. Inorg. Chim. Acta 1994, 217, 171-179.

(31) Erre, L. S.; Micera, G.; Glowiak, T.; Kozlowski, H. Chromium (III) Acetate, Chromium (III) Acetate Hydroxide, or $\mu_{3}$-Oxo-esakis$\left(\mu_{2}\right.$-acetato-O,O') - triaqua-trichromium (III) Acetate? Determining the Structure of a Complex Compound by Analytical and Spectroscopic Methods. J. Chem. Educ. 1997, 74, 432.

(32) de Oliveira, R. J.; Brown, P.; Correia, G. B.; Rogers, S. E.; Heenan, R.; Grillo, I.; Galembeck, A.; Eastoe, J. Photoreactive Surfactants: A Facile and Clean Route to Oxide and Metal Nanoparticles in Reverse Micelles. Langmuir 2011, 27, 9277-9284.

(33) Baranwal, B. P.; Fatma, T.; Varma, A. Synthesis, spectral and thermal characterization of nano-sized, oxo-centered, trinuclear carboxylate-bridged chromium(III) complexes of hydroxycarboxylic acids. J. Mol. Struct. 2009, 920, 472-477.

(34) Shaham, N.; Cohen, H.; Meyerstein, D.; Bill, E. EPR Measurements corroborate information concerning the nature of $\left(\mathrm{H}_{2} \mathrm{O}\right)_{5} \mathrm{CrIII}-$ alkyl complexes. J. Chem. Soc. Dalt. Trans. 2000, 2, 3082-3085.

(35) Reiher, M.; Salomon, O.; Artur Hess, B. Reparameterization of hybrid functionals based on energy differences of states of different multiplicity. Theor. Chem. Acc. 2001, 107, 48-55.

(36) Xia, W.; Radosevich, J.; Ellern, A. Triaqua- $\mu_{3}$-oxo-hexa- $\mu_{2}-$ propionato- $\kappa^{12} \mathrm{O}: \mathrm{O}^{\prime}$-trichromium(III) nitrate hemihydrate. Acta Crystallogr., Sect. E: Struct. Rep. Online 2006, 62, m1213-m1215.

(37) Glazunova, T. Y.; Boltalin, A. I.; Troyanov, S. I. Synthesis and crystal structure of trinuclear carboxylate complexes $\mathrm{M}_{3}\left(\mu_{3}-\mathrm{O}\right)$ $\left(\mathrm{CF}_{3} \mathrm{COO}\right)_{6} \mathrm{~L}_{3}$. Mendeleev Commun. 2004, 14, 141-143.

(38) Serre, C.; Mellot-Draznieks, C.; Surblé, S.; Audebrand, N.; Filinchuk, Y.; Férey, G. Role of solvent-host interactions that lead to very large swelling of hybrid frameworks. Science 2007, 315, 18281831.

(39) Surblé, S.; Serre, C.; Mellot-Draznieks, C.; Millange, F.; Férey, G. A new isoreticular class of metal-organic-frameworks with the MIL88 topology. Chem. Commun. 2006, No. 3, 284-286.

(40) Sydora, O. L.; Knudsen, R. D.; Baralt, E. J. Preparation of an olefin oligomerization catalyst. U.S. Patent US13323328, 2011.

(41) Our GC was not capable of separating 1-hexene and 2-hexene; 2-hexene is typically formed in low quantities in ethene trimerization reactions. Based on other literature examples, $1-\mathrm{C}_{6} / 2-\mathrm{C}_{6}$ is expected not to be lower than $95 \mathrm{~mol} \%$.

(42) Do, L. H.; Labinger, J. A.; Bercaw, J. E. Spectral Studies of a Cr(PNP)-MAO System for Selective Ethylene Trimerization Catalysis: Searching for the Active Species. ACS Catal. 2013, 3, $2582-2585$.

(43) This value is an average of two separate quantitative EPR measurements. One experiment was performed with a modulation amplitude of $1 \mathrm{G}$ and another with a modulation of 4G. Details can be found in the Supporting Information (Figure S50).

(44) Tsutsui, M.; Chang, G. Elemental Organic Compounds: Vi. Significance of П-Radical Hybridization: New Synthetic Method for Bis-Arene П-Complexes. Can. J. Chem. 1963, 41, 1255-1259.

(45) Li, T. T. T.; Kung, W. J.; Ward, D. L.; McCulloch, B.; Brubaker, C. H. Substituent effects in cationic bis(arene)chromium compounds. Electronic and ESR spectra, and an $\mathrm{x}$-ray structure of bis(1,3,5triisopropylbenzene)chromium(I) iodide. Organometallics 1982, 1, 1229-1235.
(46) Kreye, M.; Daniliuc, C. G.; Freytag, M.; Jones, P. G.; Walter, M. D. Coordination chemistry of sterically encumbered pyrrolyl ligands to chromium(ii): mono(pyrrolyl)chromium and diazachromocene formation. Dalt. Trans. 2014, 43, 9052-9060.

(47) Morosin, B. IUCr. Crystal structure of bis(benzene)chromium iodide. Acta Crystallogr., Sect. B: Struct. Crystallogr. Cryst. Chem. 1974, 30, 838-839.

(48) Rehr, J. J.; Kas, J. J.; Vila, F. D.; Prange, M. P.; Jorissen, K. Parameter-free calculations of X-ray spectra with FEFF9. Phys. Chem. Chem. Phys. 2010, 12, 5503. 